NBER WORKING PAPER SERIES

\title{
PRODUCTIVITY, SAFETY, AND REGULATION IN UNDERGROUND COAL MINING: EVIDENCE FROM DISASTERS AND FATALITIES
}

\author{
Gautam Gowrisankaran \\ Charles $\mathrm{He}$ \\ Eric A. Lutz \\ Jefferey L. Burgess \\ Working Paper 21129 \\ http://www.nber.org/papers/w21129
NATIONAL BUREAU OF ECONOMIC RESEARCH
1050 Massachusetts Avenue
Cambridge, MA 02138
April 2015, Revised January 2018

\begin{abstract}
We thank Allan Collard-Wexler, Price Fishback, Sebastian Fleitas, Jonah Gelbach, Ashley Langer, Derek Lemoine, Todd Sorensen, Elie Tamer, Bob Town, Tiemen Woutersen, and seminar attendees for helpful comments; Anatolii Kokoza for research assistance; and Jaime Duque and other data analysts at the MSHA for their assistance with MSHA data. We acknowledge financial support from a Science Foundation Arizona Grant on Sustainable Development of Critical Earth Materials. A previous version of this paper was distributed under the title "Productivity, Safety, and Regulation in Coal Mining: Evidence from Disasters and Fatalities." The views expressed herein are those of the authors and do not necessarily reflect the views of the National Bureau of Economic Research.
\end{abstract}

At least one co-author has disclosed a financial relationship of potential relevance for this research. Further information is available online at http://www.nber.org/papers/w21129.ack

NBER working papers are circulated for discussion and comment purposes. They have not been peer-reviewed or been subject to the review by the NBER Board of Directors that accompanies official NBER publications.

(C) 2015 by Gautam Gowrisankaran, Charles He, Eric A. Lutz, and Jefferey L. Burgess. All rights reserved. Short sections of text, not to exceed two paragraphs, may be quoted without explicit permission provided that full credit, including $\odot$ notice, is given to the source. 
Productivity, Safety, and Regulation in Underground Coal Mining: Evidence from Disasters and Fatalities

Gautam Gowrisankaran, Charles He, Eric A. Lutz, and Jefferey L. Burgess

NBER Working Paper No. 21129

April 2015, Revised January 2018

JEL No. D24,I18,J28,L72

\section{$\underline{\text { ABSTRACT }}$}

Underground coal mining is a dangerous industry where the regulatory state may impose tradeoffs between productivity and safety. We recover the marginal tradeoffs using disasters near a mine as shocks that increase future accident costs. We find that in the second year after a disaster, productivity decreases $11 \%$ and accident rates decrease $18-80 \%$ for mines in the same state, with some evidence that the number of managers increases. Using published "value of statistical life" and injury cost estimates, we find that the productivity loss following a disaster in the same state costs 2.51 times the value of the safety increases.

\author{
Gautam Gowrisankaran \\ Department of Economics \\ University of Arizona \\ P.O. Box 210108 \\ Tucson, AZ 85721-0108 \\ and HEC Montreal \\ and also NBER \\ gowrisankaran@eller.arizona.edu \\ Charles He \\ Department of Economics \\ University of Arizona \\ charleshe14@gmail.com
}

\author{
Eric A. Lutz \\ College of Public Health \\ University of Arizona \\ ealutz@email.arizona.edu \\ Jefferey L. Burgess \\ College of Public Health \\ University of Arizona \\ jburgess@email.arizona.edu
}




\section{Introduction}

Over the past several decades, the U.S. regulatory state overseeing worker safety has grown more rigorous and complex. For example, in the underground coal mining industry, the Mine Safety and Health Administration (MSHA) and several related laws have established a complex structure which mines must follow. Moreover, during this time period, underground coal mine productivity has declined, with regulations identified as a potential cause [Kuykendall and Qureshi, 2014, Tierney, 2016]. Figure 1 shows that productivity and accident rates for underground coal mines both declined over our sample period of 2000-14, while Figure 2 shows that regulatory penalties for these mines increased over the same period.

Figure 1: Productivity and safety at underground coal mines

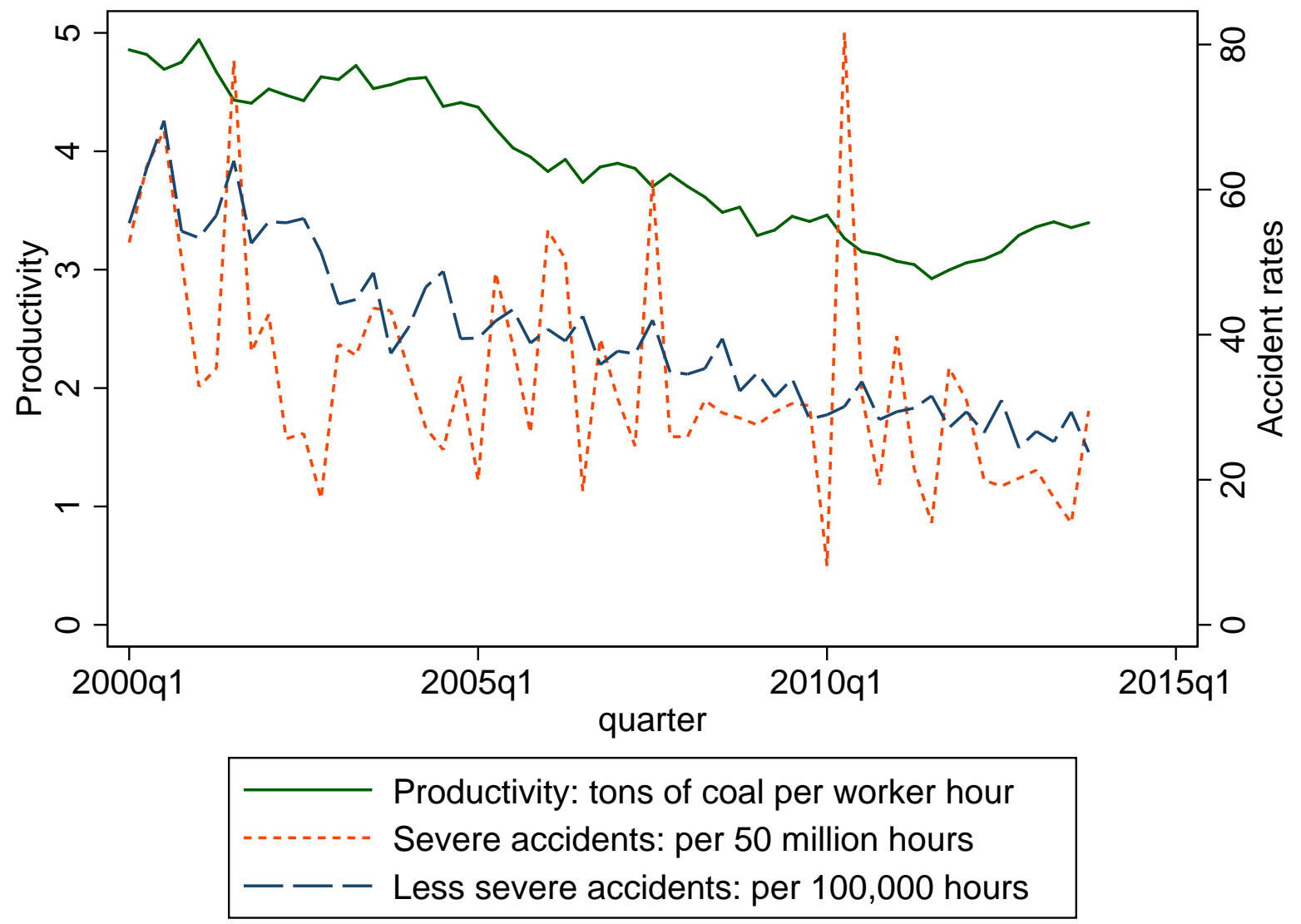

Note: authors' calculations from data and definitions described in Section 4.

The apparent tradeoffs between productivity and safety and related increase in regulatory 
Figure 2: Productivity and regulation at underground coal mines

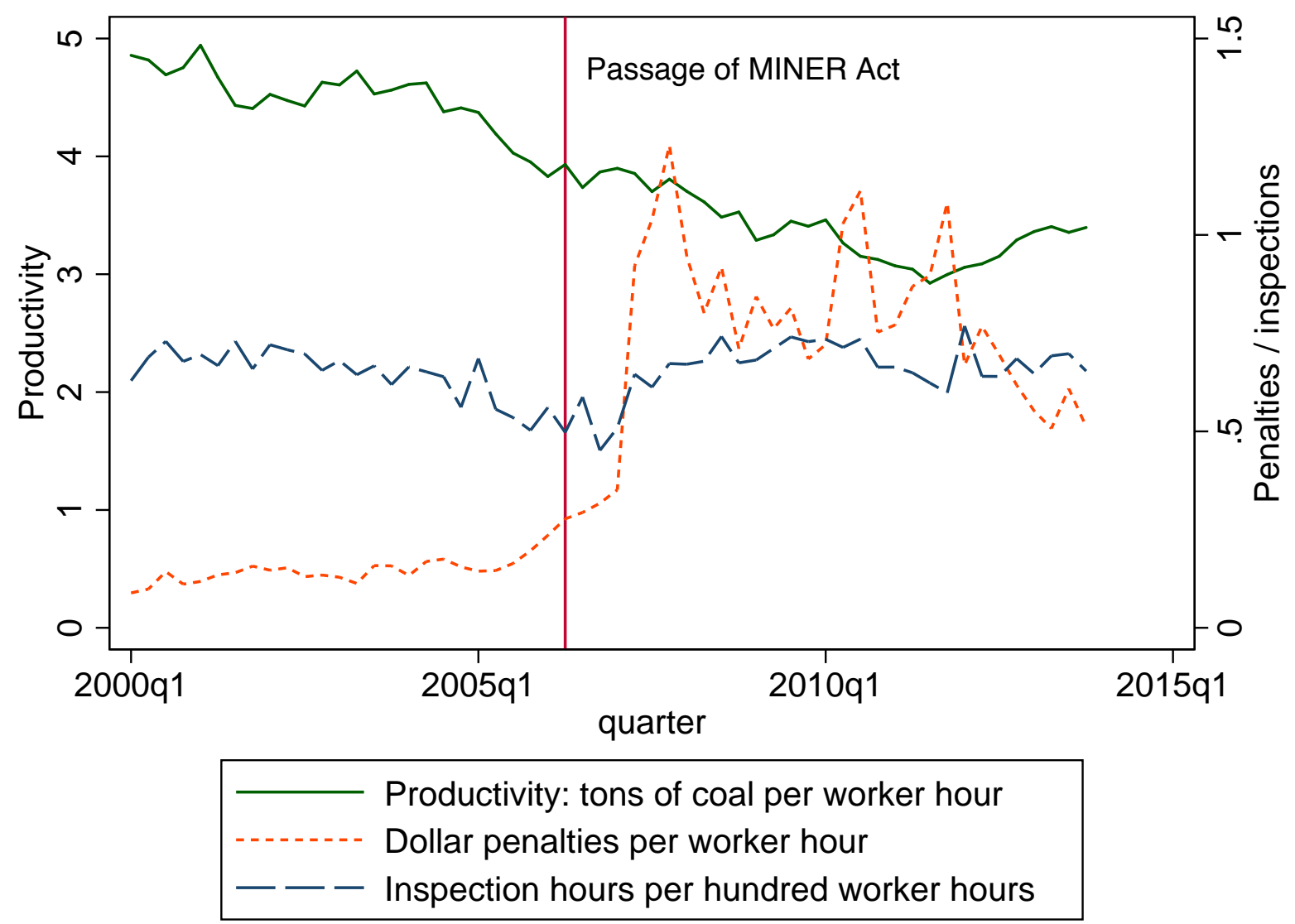

Note: authors' calculations from data and definitions described in Section 4.

enforcement suggest that it may be appropriate to view these mines as choosing expected productivity and safety, with the regulatory state imposing tradeoffs between these outputs. The principal goal of this paper is to provide evidence on whether tradeoffs between productivity and safety exist and, if so, to uncover the level of the tradeoffs that are imposed by the current regulatory environment. A related goal is to understand how events such as a mine disaster affect these tradeoffs. ${ }^{1}$ Finally, the paper develops a new identification approach —of using shocks to understand the tradeoffs imposed by regulation - that may be applicable in other settings.

We believe that understanding the tradeoffs between productivity and safety in the un-

\footnotetext{
${ }^{1}$ We define a mine disaster as an accident in a mine with five or more fatalities.
} 
derground coal mining industry is an important economic question. There has been a wideranging policy debate in recent years about the burden of the regulatory state, with controversy regarding whether regulation has had a sizable impact on productivity and growth for large swaths of the economy. ${ }^{2}$ Our study can inform this debate by evaluating whether the current regulatory environment imposes safety levels that equalize the marginal benefits of safety on fewer accidents with its marginal costs on lowering mineral productivity. Safety is one of the most important regulatory goals for underground coal mining and the sector employed over 45,000 workers in the U.S. in 2014 [Energy Information Administration, 2015]. Starting in 2017, multiple legislative and regulatory attempts were made to lessen worker safety regulations, in some cases for coal mine workers [Meier and Ivory, 2017, The Editorial Board, 2017]. Concurrently, in 2017, coal mining fatalities almost doubled, which some observers blame on "relaxed safety enforcement" under President Trump [Goodkind, 2018].

These facts suggest that the tradeoffs imposed by the current regulatory environment for underground coal mining are important and salient. In addition, our study may allow us to understand more about the tradeoffs between productivity and safety in commodity extraction and manufacturing industries more generally, many of which are at least as dangerous as coal mining. ${ }^{3}$ Finally, evaluating whether public events such as disasters affect these tradeoffs is important in evaluating how the regulatory state functions.

To analyze our research question, we use a novel identification strategy together with a panel dataset that records location, coal production, hours worked, accidents, and regulatory inspections for coal mines throughout the U.S. The detailed data allow us to measure productivity, accidents of different kinds, and regulatory enforcement. Yet, it would still be difficult to credibly evaluate the tradeoffs between safety and productivity imposed by the

\footnotetext{
${ }^{2}$ For instance, Coffey et al. [2016] find that regulation has reduced economic growth by 0.8 percentage points a year, and Greenstone et al. [2012] find that environmental air quality regulations lower productivity for polluting plants by 4.8 percent, but Levine et al. [2012] find that randomized Occupational Health and Safety Health Administration safety inspections lower injury rates with no loss in sales or employment.

${ }^{3}$ Although coal mining was once one of the most dangerous occupations by fatality rate, it is no longer in the top 10. Occupations with higher or similar death rates include fishing workers (117.0 per 100,000 full time yearly worker equivalents), logging workers (127.8), roofers (40.5), and cement and concrete manufacturing (16.0). The rate for coal mining is 18.0. (Source: U.S. Bureau of Labor Statistics. http://www.bls.gov/iif/oshwc/cfoi/cfoi_rates_2012hb.pdf. The large number of deaths in the coal mining industry reflects the large number of workers in the industry.
} 
regulatory state with a regression of a function of safety (such as accidents) on productivity: both are determined by mine choices, and unobserved factors, such as management quality or ease of coal extraction, might impact both, resulting in an endogeneity bias. For instance, mines with higher management quality may choose higher expected levels of both safety and productivity, which would make the relationship between safety and productivity appear to be positive. Simple strategies such as mine fixed effects are unlikely to adequately address the endogeneity issues since the unobservables here may vary over time for a given mine. ${ }^{4}$

Instead, we identify the joint production function of coal output and safety by using disasters and fatalities as a source of quasi-experimental variation. Our principal identification assumptions are that a disaster or fatality increases the cost of future accidents at or nearby the mine at which the death occurred and is mean independent from unobservable components of productivity or safety. The fact that accidents become more costly causes mines to make different choices regarding expected productivity and safety, which allows us to understand the tradeoffs faced by mines between these two outputs. Since both outputs change in response to the change in the regulation, we can identify the tradeoffs between them without knowing the extent of the increase in costs. This identification strategy may be useful more generally to understand tradeoffs between multiple outputs (e.g., a production good and a "bad" such as accidents or pollution) in settings where costs change but where the exact changes are not observable.

Are our identifying assumptions valid? Certainly, no fatality would be allowed to occur if it could be foreseen by workers or management, suggesting that the occurrence of a disaster or a fatality may be mean independent from unobservables. Moreover, there exist a number of plausible mechanisms through which a disaster or fatality might increase the costs of future accidents near the event. First, a disaster or fatality can lead to widespread public outrage and reprobation. For example, in the aftermath of the 2010 Upper Big Branch Mine disaster, in a public eulogy to the fallen miners, President Obama remarked that "owners responsible for conditions in the Upper Big Branch Mine should be held accountable for decisions they

\footnotetext{
${ }^{4}$ Moreover, while one mine safety law was enacted relatively recently (in 2006), it was not followed by a measurable impact on severe accidents.
} 
made and preventive measures they failed to take." ${ }^{5}$ The outrage and reprobation may lead mines to believe that there is a higher probability that a future accident would be considered negligent, in turn leading to penalties of all sorts. Moreover, we show (in Section 4) that public attention to disasters - and hence likely the outrage and reprobation - is concentrated near the affected mine. Second, a disaster or fatality might also change firm or worker perceptions regarding safety, causing them to perceive a higher future probability of accidents in the absence of a greater emphasis on safety. Finally, a disaster or fatality might increase government regulatory inspections, making the mine more likely to be penalized for safety violations, which would also increase the price of safety relative to mineral output. These effects all increase the cost of future accidents relative to the existing baseline, and hence identify the marginal tradeoffs between productivity and safety as determined by the current regulatory environment.

We develop a simple neoclassical model to formalize the tradeoffs between coal output and safety and the effect of disasters and fatalities on these tradeoffs. In our model, mines choose the levels of two inputs: production labor and safety labor. Together, these labor inputs result in expected levels of mineral output and accidents. ${ }^{6}$ Safety labor does not produce coal but instead reduces expected accident rates. This implies that an additional unit of safety labor will lower both expected productivity and expected accident rates. Thus, the model hypothesizes a tradeoff between safety and productivity.

In the model, each mine chooses the level of safety input that balances the marginal cost of having additional safety labor input against the benefits in terms of lower expected payments from accidents. Thus, mines attempt to maximize profits from expected coal production while taking into account the losses from expected accidents. We assume that disasters and fatalities increase the cost of future accidents. We allow a single fatality at a mine to impact the cost of a future accident at the mine itself and for disasters to have a broader regional impact. Given regularity conditions, an increased cost of accidents leads to a lower risk of expected accidents and fewer units of production labor. Thus, the model

\footnotetext{
${ }^{5}$ See Obama [2010]. Indeed, the CEO of Massey Energy, Donald Blankenship, was indicted in 2014 on criminal charges related to the Upper Big Branch disaster [Gabriel, 2014].

${ }^{6}$ It is equivalent to think of mines as choosing expected mineral output and accidents, as stated above.
} 
predicts that mines react to a disaster or fatality by decreasing expected accident rates at the cost of lower expected mineral productivity. If the production technology does not involve a substantial decreasing returns to scale from production workers at the margin, this will also imply a drop in expected productivity following the increase in the cost of accidents.

These testable predictions form the basis for our empirical work: we examine whether mines reduce accident rates and/or productivity after a disaster near a mine or a fatality at a mine. This allows us to evaluate whether the neoclassical model is a reasonable description of mine behavior and, if so, to evaluate the extent of the tradeoffs between productivity and safety. We also directly test one mechanism by which the cost of accidents might increase, by examining whether regulatory enforcement activity increases after a disaster or fatality.

For our empirical work, we create a panel at the mine-quarter level from 2000-14 that merges several publicly available MSHA datasets. Key variables in our data include mine location, coal production, hours worked, the number of fatalities and other accidents, and information on MSHA inspections and violations. Our regressions all use an event analysis framework. We regress dependent variables - notably productivity, accident rates, and MSHA inspections - on the occurrence of a fatality in the same mine or a disaster in the same state within the two previous years. Our regressions include mine and time fixed effects and state indicators interacted with both hours worked and number of employees as controls. We also allow for future fatalities or disasters to affect outcomes, to rule out the hypothesis that there were endogenous processes - such as an increasing difficulty in mineral extraction - that both predict the disaster or fatality and lead to declines in productivity.

We first consider disasters, by examining the effect of having a mine in the same state experience a disaster (omitting the mine with the disaster itself). We find that productivity drops $11 \%$ relative to the sample mean in the second year after the fatality. The rate of less-severe accidents per hour worked (which we define as accidents that do not cause a permanent disability or fatality) decreases by $18 \%$, while the rate of fatalities decreases by $80 \%$, both relative to their sample means, in the second year after a disaster. The pre-trends (of future disasters) are mostly insignificant for the reported regressions. Using a state-level Census dataset from 2005-13 on workers and job classifications in the coal mining sector, we 
find that the number of managers increases $41 \%$ in the second year after a disaster in the state. However, we find no evidence of increased MSHA regulatory scrutiny at other mines in the same state as the mine with the disaster. Thus, we find evidence to support our model that a disaster near a mine increases the cost of future accidents, resulting in greater safety and lower productivity.

We next consider the impact of fatalities on future outcomes at a mine. We find much smaller impacts here. Specifically, less-severe accidents drop by $14 \%$ following a fatality at the mine but there is no significant effect on severe accidents or productivity. MSHA inspections at the mine increase after the fatality, consistent with MSHA shifting resources within a local area. Thus, even though a fatality leads to a substantial change in MSHA enforcement at the mine with the fatality, the extra enforcement does not lead to significant changes in productivity or the rate of severe accidents.

Using our estimates on the reduction in productivity and accidents in the second year after a disaster, we evaluate the marginal tradeoffs between productivity and safety that are present in the current regulatory environment. Using a "value of statistical life" (VSL) estimate of $\$ 6.5$ million, ${ }^{7}$ the reduction in fatality risk two years after a disaster is equivalent to $\$ 1.69$ per hour worked. A $\$ 30,000$ estimate for less-severe accidents [National Safety Council, 2014] implies a cost savings of $\$ 0.24$ per hour worked from the reduction in this type of accident. Hence, a reasonable monetization for the benefits of the extra safety is $\$ 1.93$ per hour. If mines can hire more workers at a total cost of $\$ 40$ per hour to obtain their pre-disaster production level, the $11 \%$ productivity drop implies that they would need to add $\$ 4.84$ in wages per hour worked. Under this interpretation, the costs of the reduced productivity are 2.51 times the monetization of the benefits from the lower injury risk; they are higher under other interpretations. Thus, while mines do increase safety following a disaster at a nearby mine, using a cost-benefit approach to regulation, the regulatory state imposes a safety standard that results in marginal improvements to safety having a very high cost of lost productivity.

\footnotetext{
${ }^{7}$ An influential review article finds that the value lies between $\$ 4$ and $\$ 9$ million using U.S. labor market estimates [Viscusi and Aldy, 2003]. We are using the mid-point of these values.
} 
Related literature. Our paper builds primarily on two literatures. One literature has investigated the link between productivity and safety in coal mining and other sectors. Sider [1983] specifies and estimates a model of underground coal mining with tradeoffs between safety and production; our model builds on Sider's model. Kniesner and Leeth [2004] examine whether MSHA enforcement activities reduce mine injuries, finding very small effects. In a study of the oil extraction industry, Boomhower [2014] investigates the impact of increased liability regulations on productivity as well as safety and environmental outcomes such as well blowouts. Consistent with our results, he finds that increased liability regulations lowered both productivity and well blowouts, though, unlike in our case, the mechanism appears to be mine exits. In contrast, Hausman [2014] finds that electricity market restructuring allowed nuclear power plants to operate both more safely and more efficiently. Supporting this point of view, an occupational health and safety research has found that both productivity and safety could increase from managerial attention and training in underground mining [Fiedler et al., 1984], logging [Montorselli et al., 2010], and construction [Everett and Slocum, 1993]. ${ }^{8}$ Finally, Levine et al. [2012] and Lee and Taylor [2014] find that randomized Occupational Safety and Health Administration (OSHA) inspections lowered accident rates. Overall, we believe that we contribute to this literature by adding a novel source of identification and by quantifying the tradeoffs between productivity and safety that are implied by the current regulatory environment.

Another literature has determined the impact of regulation on productivity more generally. In addition to the studies on this topic noted above [Greenstone et al., 2012, Coffey et al., 2016, Kuykendall and Qureshi, 2014, Tierney, 2016], Gray [1987] finds that safety regulations - such as OSHA inspections - contributed as much as 30\% of the decline in productivity growth for manufacturing sectors during the 1970s. Bridgman et al. [2007] find that productivity in the sugar beet manufacturing industry declined due to regulation. Schmitz [2005] finds that labor productivity for iron ore mining doubled due to foreign competition.

\footnotetext{
${ }^{8}$ Relatedly, a different literature seeks to understand who determines safety choices. Sawacha et al. [1999] find that incentive or bonus pay can lead to decreased safety in construction and Hensher et al. [1992] find similar results for long-haul truck drivers. Other studies show that management may also have control over safety and may respond to incentives concerning worker safety [Rittenberg and Manuel, 1987].
} 
Hendel and Spiegel [2014] finds that productivity improved due to experimentation for Israeli steel mini-mills. We believe that we also contribute to this literature by providing an evaluation of whether the neoclassical paradigm - of a tradeoff between productivity and safety - holds for the underground coal mining industry and because we can quantify both the benefits (in terms of added safety) and productivity costs that are implied by the current regulatory environment at the margin.

The remainder of the paper is organized as follows: Section 2 provides background information on the industry. Section 3 exposits our model and estimation framework. Section 4 discusses the data. Section 5 discusses results. Finally, Section 6 concludes.

\section{Background}

Underground coal mining is an important industry to consider in answering questions regarding safety, productivity, and regulation. Since 1900, over 100,000 workers have been killed in coal mines in the U.S. [Alford, 1980] and many more have been injured and disabled. Underground coal miners are exposed to a wide range of hazards including gas explosions, shifting rock, falls, and machinery and mobile equipment accidents. Figure 3 shows the U.S. death rate for coal miners from 1900-2013. During this period, death rates for coal miners in the U.S. declined steadily so that they are now about 4\% of their 1900 level.

In the late nineteenth and early twentieth century, each miner worked in a "room," which is a small area of the mine that is individually allocated to a particular miner. A frequent cause of fatalities was a roof collapse in the miner's room [Fishback, 1992]. The room's roof was progressively weakened by the process of coal extraction. Therefore, each miner had control over his or her safety, as miners spent their days literally demolishing the columns supporting the roofs over their heads. Pressure on the remaining coal increased as coal was removed, which actually made further mining easier (suggesting a positive correlation between productivity and accidents within a mine over time). As miners were paid piecerate, this "softening" was one reason miners valued obtaining the maximum possible coal 
Figure 3: Historical coal mining fatalities in the U.S.

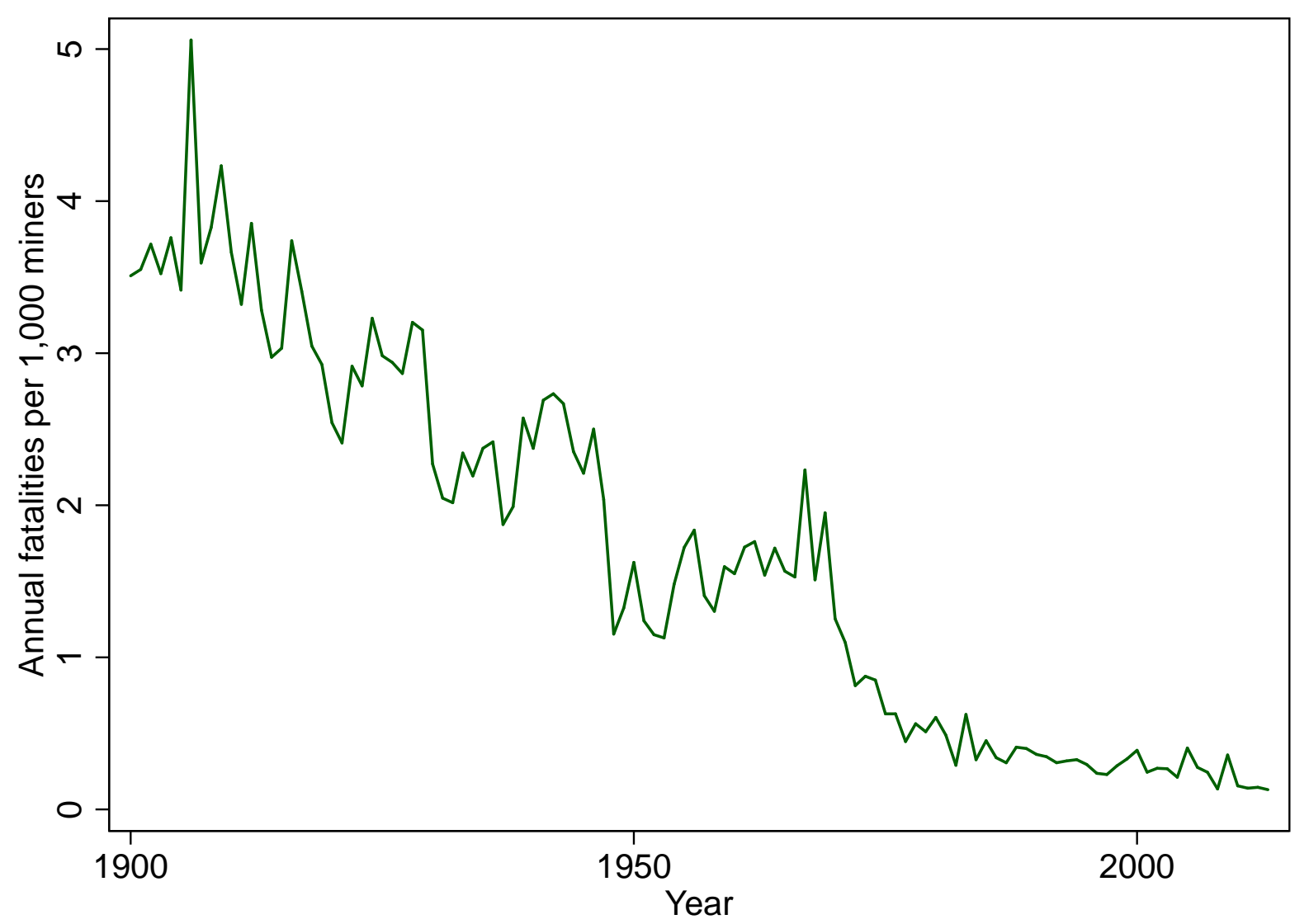

Source: authors' calculations from http://www.msha.gov/stats/centurystats/coalstats.asp.

from their room, even under conditions most would find terrifying. ${ }^{9}$ Skilled miners could reasonably estimate when a roof was about to collapse, and dig the furthest, but it was never possible to avoid collapse with certainty. Each miner worked with the knowledge there was some low but real possibility that the roof would collapse, and some were killed when this in fact occurred.

These roof collapses are a vivid and unusually direct example of balancing productivity with safety. Although this hazard no longer exists, tradeoffs can be found virtually anywhere

\footnotetext{
${ }^{9} \mathrm{~A}$ vocabulary developed that described the various sounds the roof could make. The sound of a roof groaning under reduced support was known as the "roof working". Some sounds resembled crashing thunder. It is claimed that experienced miners could detect a distinct sound that indicated imminent collapse [Brophy and Hall, 1964].
} 
there is a risk of injury in a mine. For example, speed limits on trucks or other machinery can improve safety but slow production, and safety equipment such as gloves protect workers but reduce dexterity. Mine construction involves tradeoffs between speed and structural considerations; miners still suffer fatalities from mine collapses. Finally, allowing for extra escape routes, rescue areas, and training reduces the time spent on coal extraction, but may reduce deaths in the events of a collapse.

In response to the dangers of coal mining, a significant regulatory state has been enacted by the U.S. government. The regulatory framework for this sector largely derives from the Bureau of Mines, created in 1910, the Federal Coal Mine Safety Act of 1952, the Coal Mine Safety and Health Act (generally called the "Coal Act") of 1969, the Occupational Safety and Health Act (OSHA) of 1971 [Alford, 1980], the Federal Mine Safety and Health Act of 1977, and, most recently, the Mine Improvement and New Emergency Response (MINER) Act of 2006. The 1969 Coal Act and 1977 Mine Safety and Health Act together created the Mine Safety and Health Administration, or MSHA [Weeks and Fox, 1983]. The 2006 MINER Act further advanced rules, outlined in the 1977 Act, pertaining to emergency response, mine rescue teams and their equipment, and sealing of abandoned areas of underground coal mines.

In many cases, these regulations were spurred by mine disasters. For instance, the 1952 act followed the 1951 Orient \#1 explosion that killed over 100 miners, the 1969 act followed the 1968 Consol \#9 disaster that resulted in 78 coal miner deaths, and the 1977 act followed the 1972 Sunshine Mine fire that killed 91 miners. Today, coal mines operate in a strict liability operating environment with mandated MSHA inspections - a minimum of two times per year for all surface mines and four times per year for all underground mines. Following inspections, the government can enforce regulations with punitive damages for statute violations that can range up to hundreds of thousands of dollars per violation.

We primarily consider underground coal mines even though MSHA regulates all mines, including surface coal mines and mines for other minerals. We limit our main focus to underground coal mines - rather than all coal mines - because underground coal mines are inherently more dangerous than surface coal mines and have higher rates for all types of injuries. Moreover, the coal mine disasters in our sample period in the U.S. are all from mine 
explosions or collapses at underground mines. Such events would be extremely unlikely to occur for surface coal mines. Nonetheless, we also present evidence from surface coal mines in Appendix A. We do not consider non-coal mines since MSHA does not report mineral output for these entities.

\section{Model and estimation}

\subsection{Model}

We present a simple neoclassical model of coal extraction with safety concerns and use the model to develop testable implications regarding the impact of an increase in the cost of accidents on outcomes such as safety and productivity. Our model assumes that mines are price takers on the coal and labor markets. The mine chooses non-negative values of two labor inputs: a production input $l_{p}$ and a safety input $l_{s}$. The (per-unit) wage rate for both labor inputs is $w$. Together, these choices lead to a stochastic occurrence of accidents and coal production. The mine is faced with-but does not choose - a cost per accident, $c$, which is determined by the past occurrence of fatalities and disasters. Expected profits are determined by the revenues from coal sales, the cost of labor inputs, and the cost and probability of accidents.

We now detail the mine's production functions for mineral output and safety. Expected mineral output for a mine is given by $f\left(l_{p}\right)$ and the price of coal is given by $p$. We assume that $f$ is strictly increasing in $l_{p}$. Let $A$ denote the expected accident rate per production labor input; ${ }^{10}$ we specify $A \in[0,1]$. We assume that $A$ is strictly decreasing in safety input $l_{s}$ for a given $l_{p}$. This implies that we can invert the expected accident rate function to write the safety labor input as a function of $A$ and $l_{p}$. Let $s(\cdot, \cdot)$ denote this inverse function; $s\left(A, l_{p}\right)$ indicates the level of labor safety input that is necessary to achieve expected accident rate $A$ with $l_{p}$ as the labor production input. We assume that $s$ is homogeneous of degree one in $l_{p}$. In other words, if a mine doubles the labor production input, it would have to double the

\footnotetext{
${ }^{10}$ We assume that injuries can only occur to workers when engaged in production tasks.
} 
labor safety input in order to maintain the same expected accident rate. The homogeneity assumption allows us to write $l_{s}=s\left(A, l_{p}\right)=l_{p} g(A)$, where $g(A)$ is some monotonically decreasing function. Effectively then, the mine chooses $l_{p}$ and $A .^{11}$

Using these production functions, mine expected profits can be written as:

$$
\pi\left(l_{p}, A \mid c\right)=p f\left(l_{p}\right)-c l_{p} A-w\left(l_{p}+s\left(A, l_{p}\right)\right)=p f\left(l_{p}\right)-c l_{p} A-w\left(l_{p}+l_{p} g(A)\right) .
$$

In (1), the first term is the expected revenue from coal production. The second term is the expected cost of accidents. The final term is the wage bill for the chosen production and safety labor inputs. We assume that the production functions $f$ and $g$ are twice differentiable and that they satisfy regularity conditions that guarantee that there is a unique interior maximizer to $l_{p}$ and $A$. This would be the case if $f$ were concave and if $g$ were convex, for instance.

Having specified our model, we now exposit the first-order conditions (FOCs) for profit maximization with respect to the production labor input:

$$
\frac{\partial \pi\left(l_{p}, A \mid c\right)}{\partial l_{p}}=p f^{\prime}\left(l_{p}\right)-c A-w(1+g(A))
$$

and the safety labor input:

$$
\frac{\partial \pi\left(l_{p}, A \mid c\right)}{\partial A}=-c l_{p}-w l_{p} g^{\prime}(A)
$$

Equation (2) states that a mine adds production labor input until its marginal product in terms of mineral production is equal to the wage plus the the cost of accidents plus the marginal extra safety labor input needed to keep the accident rate constant. It differs from a standard production FOC in the $-c A$ and the $-w g(A)$ terms. Equation (3) states that mines set the expected accident rate so that the expected cost of an additional accident, $c l_{p}$ is equal to the marginal product of a safety worker in reducing accidents, $w l_{p} g^{\prime}(A)$. Define $l_{p}^{*}(c)$ and $A^{*}(c)$ to be the profit maximizing choices of production labor input and expected

\footnotetext{
${ }^{11}$ We focus on $A$, rather than $l_{p}$ as the choice variable because we want to prove monotonicity of $A$ in the cost of accidents.
} 
accident rates respectively.

We now turn to our main result, which is that we will observe a decrease in labor production input and in the expected accident rate following a disaster or fatality which raises c. Formally:

Proposition 1. $l_{p}^{*}(c)$ and $A^{*}(c)$ are decreasing in $c$.

Proof We prove monotonicity of the optimal choices using Amir [2005], which is based on supermodularity as developed by Topkis [1978]. Amir Theorem 9, conditions (i) and (ii) require that the second derivatives $\frac{\partial^{2} \pi}{\partial\left(-l_{p}\right) \partial(-A)}, \frac{\partial^{2} \pi}{\partial c \partial\left(-l_{p}\right)}$, and $\frac{\partial^{2} \pi}{\partial c \partial(-A)}$ all be weakly positive, or equivalently that $\frac{\partial^{2} \pi}{\partial l_{p} \partial A} \geq 0, \frac{\partial^{2} \pi}{\partial c \partial l_{p}} \leq 0$, and $\frac{\partial^{2} \pi}{\partial c \partial A} \leq 0$.

First, $\frac{\partial^{2} \pi}{\partial l_{p} \partial A}=-c-w g^{\prime}(A)$. But, (3) implies that $-c=w g^{\prime}(A)$. Thus, $\frac{\partial^{2} \pi}{\partial l_{p} \partial A}=0$. Second, $\frac{\partial^{2} \pi}{\partial c \partial l_{p}}=-A<0$. Finally, $\frac{\partial^{2} \pi}{\partial c \partial A}=-l_{p}<0$. Amir Theorem 9 condition (iii) is satisfied by our assumptions of differentiability and convexity of the choice sets for the inputs.

Note that Proposition 1 leverages the assumption that $s\left(A, l_{p}\right)$ is homogeneous of degree 1 in $l_{p}$ to ensure that the cross derivatives of profits at any profit-maximizing choice of inputs will be 0 . Without this assumption, it is possible that the monotonicity result will not hold.

We believe that Proposition 1 is intuitive. In a neoclassical model, mines choose safety levels to balance the accident cost with the production losses from safety. A fatality or disaster increases the cost of future accidents. This increases the mine's marginal benefits to improving safety, causing the mine to choose a greater safety labor input. The true marginal product of production labor input in producing mineral output falls as a result, causing the mine to choose a lower $l_{p}$.

Note that the decrease in production labor input following the increase in $c$ implies that there will be less expected mineral production. A related question is whether expected mineral productivity will fall. We can define expected mineral productivity as coal output per labor input, or

$$
Y=\frac{f\left(l_{p}\right)}{l_{p}+s\left(A, l_{p}\right)} .
$$

Following an increase in $c$, the lower expected accident rate and homogeneity assumption on $s\left(A, l_{p}\right)$ imply that there will be more safety labor input relative to production labor input 
than before the accident cost increase. Thus, if the economies of scale in mineral production are constant - or not declining too much over the range of expected mineral production chosen between the old and new accident cost - then expected mineral productivity will drop following the increase in accident cost.

Overall, we believe that an increase in accident cost is likely to lead to a loss in expected productivity, when measuring expected productivity as mineral output per worker. In addition, our specifications include measures of hours worked as regressors in order to control for potential changes in economies of scale.

\subsection{Estimation framework}

As derived in Section 3.1, our model predicts that an increase in the cost of accidents, as caused by a past fatality or disaster, will decrease in the expected accident rate $A$ following a disaster or fatality. It also predicts that an increase in the cost of accidents will decrease expected mineral productivity $Y$, conditioning on returns to scale. We are ultimately interested in the tradeoff between expected accidents and expected mineral productivity given mine optimization. We can write this tradeoff as

$$
\frac{\partial Y}{\partial A}=\frac{\frac{\partial Y}{\partial c}}{\frac{\partial A}{\partial c}}
$$

From (4), we uncover the tradeoff between accidents and mineral productivity by evaluating the impact of a disaster or fatality shock on productivity and accident rates, and taking the ratio between these two derivatives. We evaluate the tradeoff $\frac{\partial Y}{\partial A}$ along the path chosen by mines faced with different accident $\operatorname{costs} c$. Importantly, (4) shows that by taking the ratio of two observables, we can identify the tradeoffs between productivity and safety knowing only the presence, and not the size, of the cost shock.

We proceed by specifying regressions that examine the extent to which productivity, accidents per hour, and related measures are affected by past mine disasters or fatalities. Specifically, for disasters and productivity, we perform regressions at the mine-quarter level 
that take the form:

$$
Y_{i t}=\alpha_{i}+\gamma_{t}+\beta_{1} \mathbb{1}\left\{d_{i t+1}\right\}+\beta_{2} \mathbb{1}\left\{d_{i t}\right\}+\beta_{3} \mathbb{1}\left\{d_{i t-1}\right\}+\beta_{4} X_{i t}+\varepsilon_{i t},
$$

where $i$ denotes a mine and $t$ a calendar quarter, $\alpha_{i}$ are mine fixed effects, $\gamma_{t}$ are time (quarterly) fixed effects, $\mathbb{1}\left\{d_{i t}\right\}$ is an indicator for a disaster in the same state as the mine, ${ }^{12}$ $X_{i t}$ represent other covariates such as hours worked interacted with the state, $\beta_{1}, \ldots, \beta_{4}$ are parameters, and $\varepsilon_{i t}$ represents the deviations between the realized values of the dependent variables and their expectations, e.g. between the number of accidents and the expected number given the labor inputs. For accidents, we use similar regressions, but with $A_{i t}$ instead of $Y_{i t}$ as the dependent variable.

Our main regressors of interest are the indicators for a current or past disaster near a mine, $\mathbb{1}\left\{d_{i t}\right\}$ and $\mathbb{1}\left\{d_{i t-1}\right\}$. Because our hypothesis is that a disaster near a mine changes the relative cost of accidents, the coefficients on these indicators specify the deviation in cost from the baseline multiplied by the change in the expected outcome given the change in cost. While we are principally interested in the impact of a past accident, we also include regressors that measure the presence of a future disaster, $\mathbb{1}\left\{d_{i t+1}\right\}$. This inclusion forms a falsification test that would allow us to reject the causal interpretation of a disaster or fatality. For instance, if we observe that a future fatality predicts a significantly higher accident risk, we might infer that the mine has undergone a period of low safety relative to its long-run average. We might then believe that the higher accident risk led to the fatality, rather than that the fatality changed the price of safety which led to differential accident risk, as we assume in our model. Thus, our model will tend to be more plausible to the extent that the future indicators are not significant predictors.

In different regressions, $\mathbb{1}\left\{d_{i t}\right\}$ is an indicator for either a disaster or a fatality. For our regressions where $\mathbb{1}\left\{d_{i t}\right\}$ indicates disasters, we specify that the price of safety may change if there is a disaster located near the mine, consistent with a disaster being widely known and intensely scrutinized in an immediate area. For our regressions where $\mathbb{1}\left\{d_{i t}\right\}$ indicates

\footnotetext{
${ }^{12}$ Our regressions include several quarterly indicators for lagged and future disasters, but we show one lag in (5) for brevity.
} 
a fatality, we do not believe (and verified in unreported results) that there will be a wider change in the price of safety. Hence, we specify that the price of safety can change only for the mine with the fatality itself. In all cases, we drop the five mines with a disaster, because other factors besides a change in the price of safety, such as physical damage, may be affecting their mineral output and safety choices.

In (5), we include mine fixed effects to account for differences in geology, type of coal, and technology across mines. By including mine fixed effects, we are controlling for the baseline risk at each mine in evaluating how past disasters and fatalities affect safety choices. Our estimates thus reflect the change in productivity or accident rates after the disaster or fatality. Our covariates include time fixed effects because safety technologies and regulations have changed over time and because different input prices might cause mines to make different tradeoffs over time. We cluster standard errors two ways, at the state-quarter and mine levels. We weight all regressions by the mean hours worked at a mine, because mines with more hours worked may provide more information.

In addition to the regressions based on (5) we also specify regressions that consider the mechanisms whereby a past disaster or fatality might increase the cost of future accidents. The central mechanism that we consider is regulation through MSHA. The format of these regressions is the same as (5) except that the dependent variable for these regressions indicates MSHA regulatory visits and enforcement.

Our main identification assumption is that $\mathbb{1}\left\{d_{i t}\right\}$ and other regressors are exogenous, or in other words that they are mean independent from $\varepsilon_{i t}$. This will be satisfied if either the disaster or fatality was not related to the mine being more unsafe than usual in a quarter relative its baseline safety level or if the shock that caused the disaster or fatality were independent from $\varepsilon_{i t}$. In the case of disasters or fatalities, endogeneity would only occur if there were spatially and serially correlated shocks to safety and productivity relative to baseline levels that predicted disasters. In the case of fatalities, endogeneity could occur if there was serial correlation of outcomes within a mine. In both cases, the pre-trends would likely be significant if the disasters or fatalities were endogenous.

Finally, we include some regressions where the unit of observation is the state-year. These 
regressions use data on occupations within the mining sector that are only available at this level of aggregation. For these regressions, we cluster standard errors at the state level and weight regressions by the mean number of workers in the state.

\section{Data}

We obtained most of our data from MSHA. We merge several datasets, all of which we downloaded from the "Data Sets" area on the MSHA.gov website. The datasets report information on coal and metal mines. For our main analyses, we keep only records that pertain to underground coal mines. The Employment/Production Data Set (Quarterly) indicates the total coal production, the number of employees, U.S. state of location, and number of hours worked for all coal mines in the U.S. at the quarterly level from 2000 through the third quarter of 2014. Figure A.1 in Appendix A provides summary statistics on the total underground coal production by state over our estimation sample; our primary dataset includes 17 states.

The Accident Injuries Data Set reports detailed information for all coal mining accidents in the U.S. From this database, we use the reported degree of injury. A fatality is a degree 1 injury, and an injury resulting in a permanent partial or total disability is a degree 2 injury. We classify accidents that result in degree 1 and 2 injuries as severe accidents. We classify injuries of degrees 3-6 as less-severe accidents. We exclude injuries of degrees 7-10, which include injuries from natural causes and injuries for non-employees. ${ }^{13}$

The Violations Data Set reports the number of violations and financial penalties that mines were assessed from MSHA inspectors during each quarter. The Inspections Data Set reports the number of inspections in a mine and the total hours each mine is inspected. Finally, the Mines Data Set provides latitude and longitude information for each mine.

Table 1 provides details on injury by degree during the period of our data. Fatalities are the most rare, with 295 observed over this period. Permanent disabilities occur slightly more often than fatalities, with 550 observed over the same period. Among the less-severe

\footnotetext{
${ }^{13}$ Some studies have found that U.S. government data may undercount non-fatal workplace injuries [Leigh et al., 2004]. We do not adjust our data for reporting errors, since we do not have any alternate data sources.
} 
accidents, the most common are accidents with injuries that require days away from work only, with 29,642 observed, followed by ones that require no days away from work, but still require medical treatment, with 14,166 observed.

Table 1: Underground coal mine accident occurrences in U.S.

\begin{tabular}{l|ccc} 
Injury degree & $\begin{array}{c}\text { Accident } \\
\text { description }\end{array}$ & $\begin{array}{c}\text { Severe } \\
\text { injury }\end{array}$ & $\begin{array}{c}\text { Number } \\
\text { observed }\end{array}$ \\
\hline Cases resulting in death & 1 & Yes & 295 \\
Cases with permanent total or partial disability & 2 & Yes & 550 \\
\hline Cases with days away from work only & 3 & No & 29,642 \\
Cases with days away from work and restricted work & 4 & No & 2,534 \\
Cases with days of restricted work only & 5 & No & 3,024 \\
Cases without days away from work but with medical & 6 & No & 14,166 \\
treatment & & &
\end{tabular}

Note: sample period is Q1:2000 through Q3:2014.

Figure 4 graphs annual fatalities and disasters over time during the period of our data. ${ }^{14}$ We define a disaster as an accident with five or more fatalities. We observe five disasters, two in West Virginia, and one in each of Utah, Kentucky and Alabama. All disasters, including the mine and state in which they occurred, are noted on the figure. The Upper Big Branch Mine disaster killed 29 people, the most of the five disasters in our sample. The Crandall Canyon Mine disaster was caused by a mine collapse while the remaining disasters in our sample were caused by the ignition of explosive gases.

We chose five as the threshold number of fatalities that defines a disaster as we believed that this number would represent a cutoff for generating more widespread attention. Note also from Figure 4 that four out of the five disasters that we observe have far more than five fatalities. Also, most non-disaster fatalities represent single fatalities. In particular, we observe 197 mine/months with 1 fatality, 12 mine/months with 2 fatalities, 2 mine/months with 3 fatalities, and none with 4 fatalities. We believe that this evidence shows that there is a sharp division between the disasters and the non-disaster fatalities.

Our identification rests on a disaster changing the cost of future accidents in a local area relative to the national change, in part due to public outrage and reprobation, which require

\footnotetext{
${ }^{14}$ Our data from 2014 only report fatalities for Q1-3:2014.
} 
Figure 4: Fatalities and disasters in underground coal mines

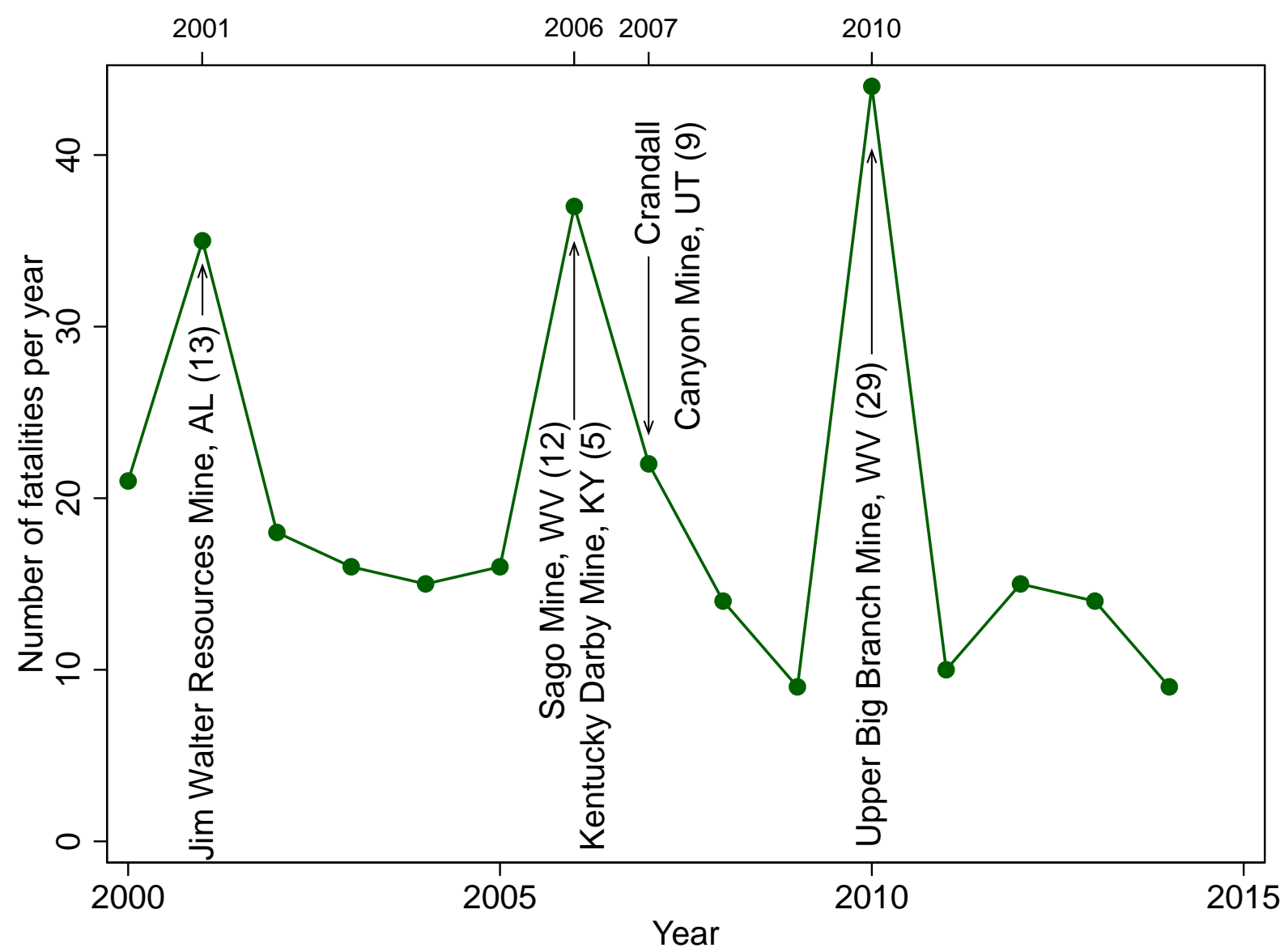

Note: number of deaths for each disaster reported in parentheses. The nine people who died in the Crandall Canyon disaster include three rescue workers who were killed ten days subsequent to the initial collapse.

public attention. Figure 5 shows how Google web searches for "mining accident" correlate with disasters for the four disasters that are in our sample and are recent enough to have web search data from Google. The Crandall Canyon Mine disaster in Utah correlates with by far the most searches in Utah; the other disasters had little impact there. ${ }^{15}$ In contrast, the West Virginia and Kentucky disasters led to the maximum search intensity in those states. ${ }^{16}$ Thus, we believe that the results show that public attention to a mine disaster is much higher in a relatively local geographic area around a disaster than for the U.S. as a whole, which

\footnotetext{
${ }^{15}$ Google does not report the number of searches, instead normalizing the highest search intensity to 100. Thus, we cannot compare the relative importance of disasters across states, only across time within a state.

${ }^{16}$ Note that Kentucky and West Virginia are neighboring states, suggesting that the effect of a disaster, though local, is not strictly constrained by state boundaries.
} 
Figure 5: Google trends index for "mining accident," in U.S. and states with disasters
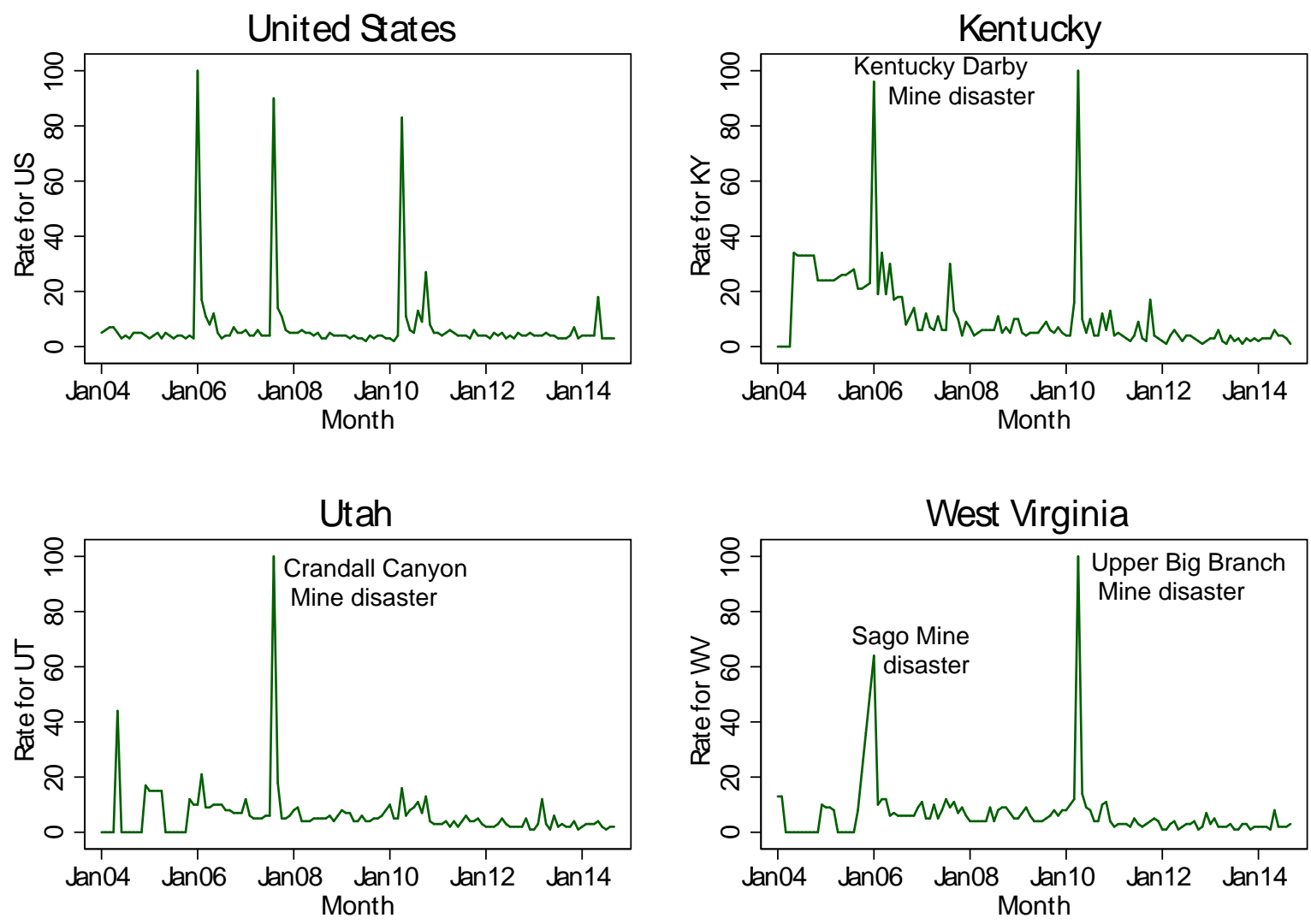

Note: figure constructed by authors from data from http://trends.google.com using web searches for all categories. Rates (as reported by Google) are web search frequencies with maxima normalized to 100.

will ultimately be reflected in the costs of future accidents.

The MSHA production and accident databases are reported separately by each subunit within a mine. To create our estimation sample, we remove all observations that are in subunits that indicate office work instead of mining activity. We then collapse the data so that our unit of observation is a mine observed over a quarter. We define productivity as coal production measured in tons divided by person-hours of labor. Our data on MSHA violations and actions are reported at the mine-quarter level so we do not collapse these data.

Our analysis sample drops mines which never produced coal during our sample period. We also drop mine-quarter observations which reported fewer than 2,000 person hours, which is the equivalent of four full-time employees over the quarter. Last, as noted above, we exclude 
from our sample the five mines which experienced a disaster.

Our data extend from Q1:2000 through Q3:2014. Our regressors include lags and leads of disasters and fatalities up to two years. This limits our sample that uses fatalities to Q1:2002 through Q3:2012. However, because mine disasters are large, public events, we know when they occurred. The most recent mine disaster prior to our sample was in 1992, more than two years preceding our earliest data. Thus, for our regressions which include mine disasters as the main regressor, we can keep observations going back to Q1:2000.

Table 2 provides summary statistics on our estimation sample at the mine-quarter level. We include here all observations from Q1:2000 through Q3:2012, which corresponds to the sample with disasters as the main regressor; the sample with fatalities as the main regressor starts in Q1:2002. The mean hours worked is about 45,100, reflecting a mean mine size with a full-time equivalent of 90.2 workers. The largest mine is about 15 times this size. Mean coal production is about 174,200 tons per quarter. Mean productivity is 3.1 tons per worker hour. $^{17}$

Table 2: Summary statistics at mine-quarter level

\begin{tabular}{l|ccccc} 
Variable & Mean & Std. dev. & $\begin{array}{c}\text { Mean within- } \\
\text { mine std. dev. }\end{array}$ & Min & Max \\
\hline Coal production (thousands of tons) & 174.2 & 360.4 & 69.2 & 0 & 3,091 \\
Hours worked (thousands) & 45.1 & 70.4 & 15.1 & 2 & 698 \\
Employees & 78.4 & 119.4 & 24.3 & 2 & 1,164 \\
Productivity (tons per hour) & 3.1 & 2.2 & 1.2 & 0 & 30 \\
Less-severe accidents per million hours & 45.0 & 81.0 & 56.9 & 0 & 3,077 \\
Severe accidents per million hours & 0.8 & 10.1 & 3.4 & 0 & 556 \\
Fatalities per million hours & 0.3 & 6.5 & 1.3 & 0 & 467 \\
\hline MSHA inspections & 6.1 & 7.1 & 2.6 & 0 & 58 \\
MSHA inspection hours & 278.7 & 322.4 & 125.9 & 0 & 8,526 \\
MSHA penalties (thousands of $\$)$ & 22.3 & 70.0 & 32.9 & 0 & 1,982 \\
MSHA violations & 28.3 & 36.6 & 18.0 & 0 & 470 \\
\hline
\end{tabular}

Note: summary statistics are for the estimation sample for underground mines for specifications that have disasters as the main regressor. Sample period is Q1:2000 through Q3:2012. N=24,035. See text for details of sample construction and variable definitions.

Despite the high absolute numbers noted in Table 1, severe accidents are rare, with a

\footnotetext{
${ }^{17} \mathrm{MSHA}$ (and our paper) use the short ton, which is equal to 2,000 pounds.
} 
rate of 0.8 per million hours worked. One million hours worked corresponds to 2,000 people working full-time over a quarter. Less-severe accidents occur an average of 45.0 times per million hours worked, suggesting that a larger mine with 1,000 workers would expect to have 22.5 less-severe accidents each quarter. MSHA inspects underground coal mines 6.1 times per quarter on average spending an average of 278.7 hours on each inspection. They also assess penalties of $\$ 22,300$ on average per mine-quarter, finding 28.3 violations on average.

For each reported statistic other than productivity, the standard deviation is larger than the mean. This indicates that there is substantial variation in all the variables in our data. This variation reflects the diversity of mining operations in the U.S., which vary in size from small mines employing a handful of workers to massive sites employing over a thousand workers. Different mines also have very different rates of MSHA inspections and assessed violations and penalties.

In addition to MSHA data, we also obtained U.S. Census data from the Integrated Public Use Microdata Series [IPUMS, Ruggles et al., 2010]. We use the American Community Survey (ACS) data from IPUMS, which began in 2005. For our purposes, the ACS data list worker occupations for a sample of workers employed in the coal mining industry. These data allow us to understand variation in the effects of a disaster in a state by occupation. Unlike the MSHA data, which are at the mine-quarter level, these American Community Survey data are only available at the state-year level and pertain to both underground and surface coal mines.

We extracted data from IPUMS for all employees reported coal mining as their industry, using the 1990 industry code 41, and who reported working during the past 12 months in the "workedyr" field. We use the "occ1990" field as our measure of occupation. We split coal-mining workers into three occupations based on this field: coal miners (defined as an occupation of "mining machine operators"), managers (defined as an occupation whose name includes the word "manager" or "supervisor"), and other workers.

The American Community Survey data include survey weights and we collapse the data to the state-year level using these weights. The data extend from 2005 through 2013, a shorter time period than our overall study period, thus limiting the power of this analysis. 
Table 3: ACS state-year level data summary statistics

\begin{tabular}{l|ccccc} 
Variable & Obs. & Mean & Std. dev. & Min & Max \\
\hline Number of workers (thousands) & 219 & 4.1 & 6.0 & 0.0 & 29.3 \\
Number of miners (thousands) & 219 & 1.0 & 1.5 & 0.0 & 7.7 \\
Number of managers (thousands) & 219 & 0.6 & 0.8 & 0.0 & 3.9 \\
Number of other workers (thousands) & 219 & 2.6 & 3.8 & 0.0 & 19.2 \\
\hline Mean income of workers (thousands of $\$$ ) & 219 & 61.0 & 24.4 & 11.1 & 253.8 \\
Mean income of miners (thousands of $\$$ ) & 171 & 53.2 & 19.0 & 0.8 & 165.5 \\
Mean income of managers (thousands of $\$$ ) & 179 & 87.7 & 39.2 & 0.0 & 301.0 \\
Mean income of other workers (thousands of $\$$ ) & 215 & 56.7 & 21.1 & 12.3 & 176.9 \\
\hline
\end{tabular}

Note: summary statistics are for the ACS data and extend from 2005 through 2013.

Table 3 provides summary statistics on the ACS data. Our ACS data include 219 stateyear observations, all of which have some employed workers in the coal mining industry. Miners comprise about $24 \%$ of the employees in this sector, managers $15 \%$, and other occupations $63 \%$. Mean annual wage and salary income in the sector is $\$ 61,000$, and is higher for managers (at $\$ 87,700$ ) than for coal miners (at $\$ 53,200$ ).

\section{Results}

\subsection{Effect of nearby mine disasters for underground coal mines}

We first consider the question of whether a disaster lowers productivity and accidents for nearby mines by raising their cost of future accidents, using regressions based on (5). Our specifications include quarterly coefficients for being in the state and within two years of the mine disaster, using specifications estimated at the mine-quarter level. Thus, our coefficients will capture the effects of being within two years of the disaster relative to being outside this window.

Figure 6 (and our other figures) report our main results by graphing the coefficients on current, future, and lagged fatalities, along with error bars that report $95 \%$ confidence intervals. Our figures divide the estimated regression coefficients by the sample mean values of the dependent variables (as reported in Table 2) to be able to directly compare the magnitudes 
of the effects. Appendix A reports tables with the corresponding coefficient values for each figure in the main paper.

Figure 6: Effects of a disaster in state on productivity and safety
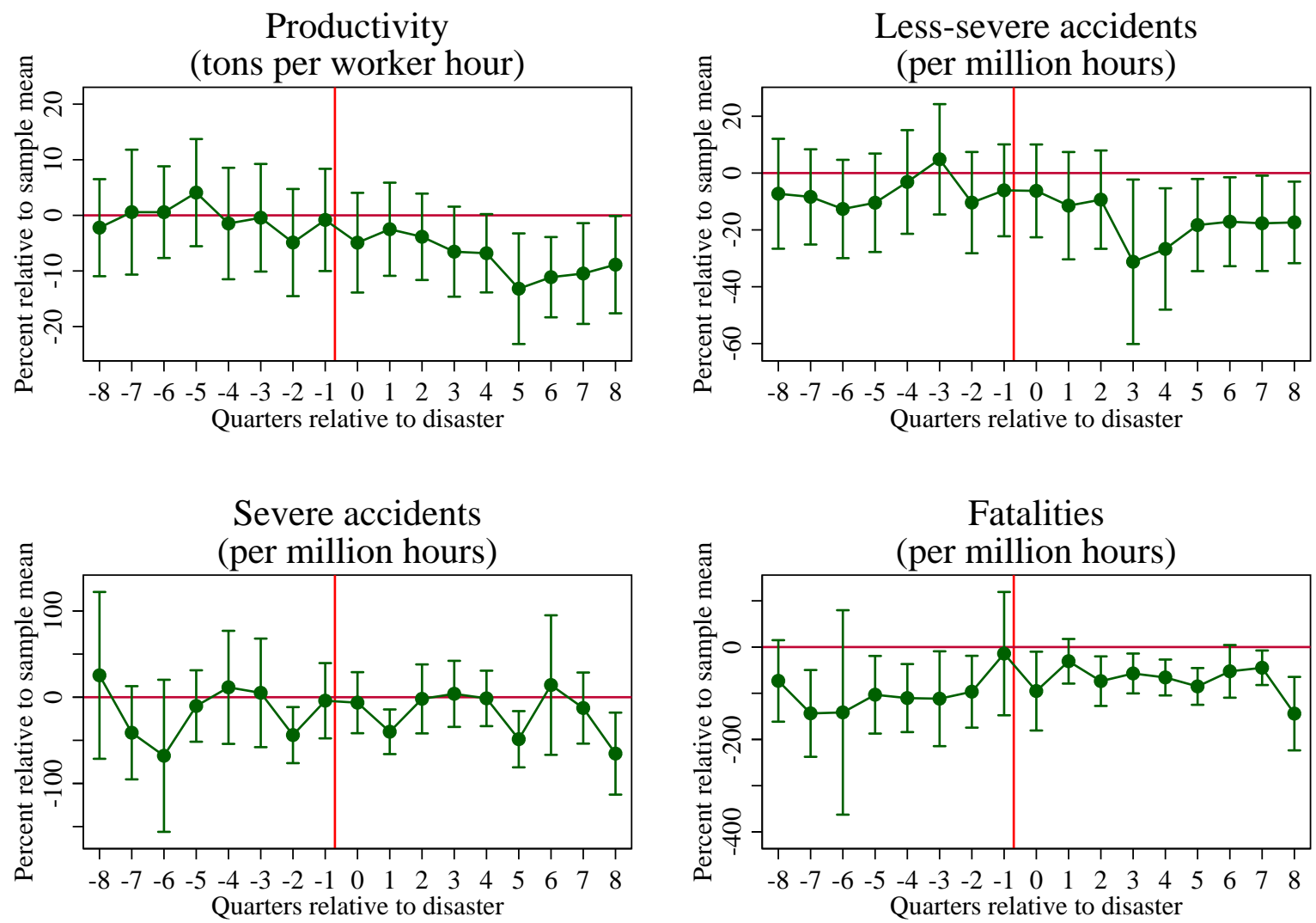

Note: each box reports selected regressors from one regression and each dot is a regression coefficient expressed as a percent of the sample mean of the regressor. Dependent variables are indicated in the titles. Each regression includes the following additional regressors: mine fixed effects, quarter fixed effects, state fixed effects interacted with hours worked, and state fixed effects interacted with number of employees, and is weighted by the mean number of workers at the mine. The vertical lines show $95 \%$ confidence intervals, based on standard errors clustered two ways at the state-quarter and mine levels.

We find that a disaster near a mine lowers productivity significantly starting in the fifth quarter after the disaster. The mean of the four coefficients in the second year after the disaster is -0.33 tons per worker hour, which represents an $11 \%$ drop in productivity relative to the sample mean. Though negative, the coefficients during the quarter of the disaster and the first four quarters after the disaster are not significant at the $5 \%$ level. The pre-trend 
coefficients of a future disaster are also not significant and have point estimates close to 0 . Recall that the pre-trends are included as a falsification measure of the hypothesis that a disaster is an unforeseen event that shocks the cost of future accidents. Thus, the lack of significance suggests that the disaster is causing the change in productivity rather than the result being due to unobserved local factors that correlate with a disaster.

Turning to accidents, we find that a disaster in a state predicts a significantly lower rate of less-severe accidents, starting in the third quarter after the disaster. The mean of the coefficients in the second year after the disaster represent a drop of $18 \%$ in the rate of these accidents. Again, the pre-trends are not significant, and have point estimates that are much closer to 0 .

We also find that fatalities drop following a disaster. The effects are large: we estimate a mean of -0.24 for the four coefficients in the second year after the disaster, representing an $80 \%$ drop relative to the sample mean. However, three of the eight coefficients in the two years before the disaster are also significantly negative. This suggests that we should be cautious about a belief that the true magnitude of the effect is as large as our estimate. Finally, we find no consistent significant effect on severe accidents before or after a disaster in a state. However, some of the magnitudes of the coefficients on severe accidents post-disaster are consistent with the significant drop on fatalities, and indeed, severe accidents are a major component of fatalities (Table 1). In this case, the pre-trends are insignificant and small in magnitude, adding some credence to the causal story here.

Overall, our results show that a disaster appears to increase safety and reduce productivity, consistent with our model; Section 5.3 below discusses the magnitudes of the tradeoffs between productivity and safety. It is worth noting that some of the impact of a mine disaster may be national. Our estimation will capture national effects of the disaster through time dummies and hence our estimate of the impact of the disaster will only capture the effect of the change in price from the part of the effect that is local.

We next seek to understand how a disaster in a state changes the number and composition of coal mining workers in the state, using the ACS data and regressions at the state-year level. Since our data here pertain only to 2005-13, they contain only four disasters. Moreover, 
Figure 7: Effects of a disaster on the number of coal mining workers in state, by category
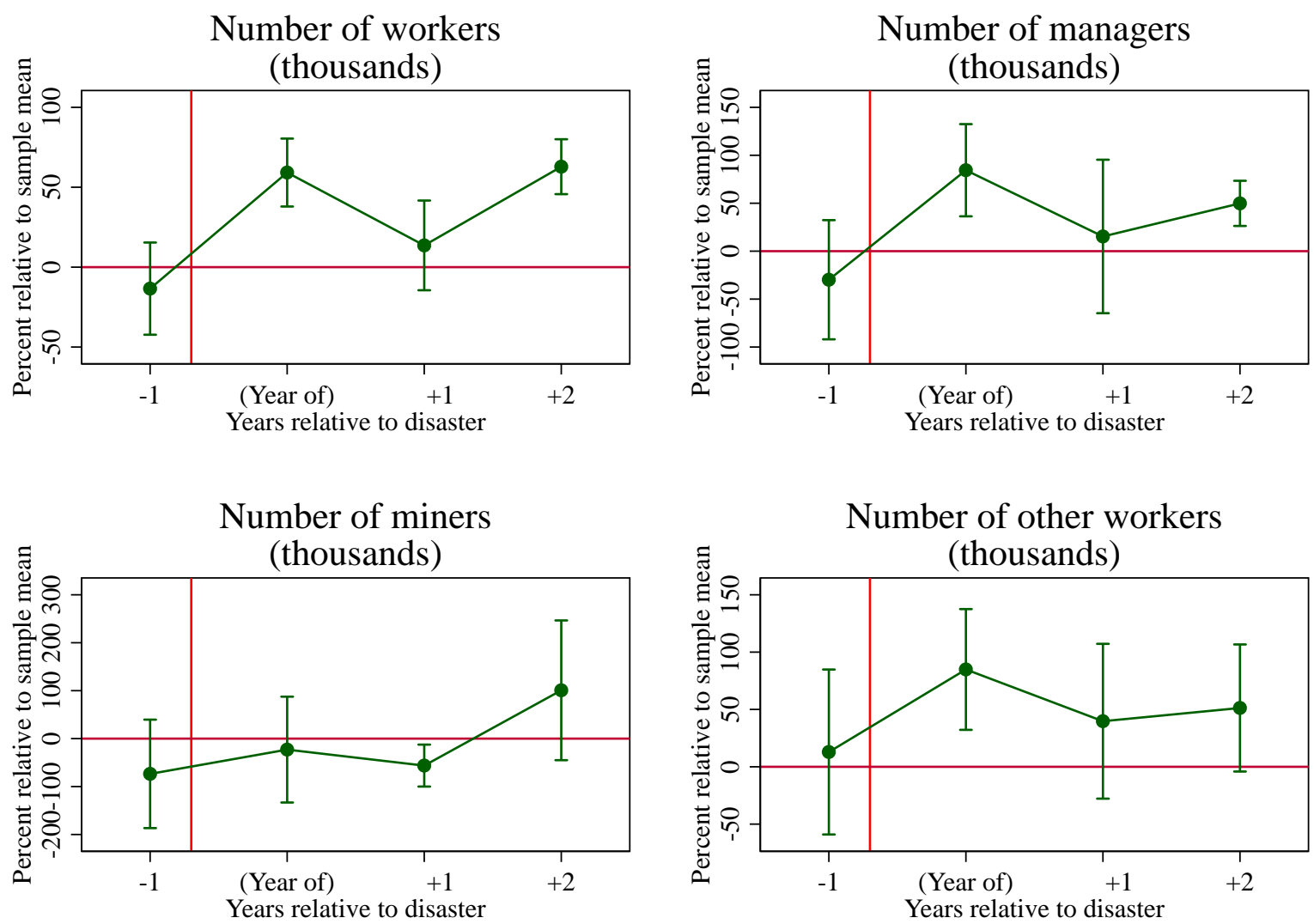

Note: regressions use state-year level ACS data. Each box reports selected regressors from one regression and each dot is a regression coefficient expressed as a percent of the sample mean of the regressor. Dependent variables are indicated in the title. Each regression includes the following additional regressors: state fixed effects, year fixed effects, and logged state GDP per capita, and is weighted by the mean number of workers in the state. Standard errors are clustered at the state level.

we omit the falsification indicators for being two years before a disaster (but include the indicators for being one year or less before a disaster), as otherwise, we would be reduced to having two disasters in our sample. ${ }^{18}$

Our results are presented in Figure 7. We find that in the year after a disaster, there are fewer employed coal miners in the state of the disaster, but that this coefficient rebounds to a positive but insignificant point estimate in the second year after the disaster. We also

\footnotetext{
${ }^{18} \mathrm{Also}$, unlike our base regressions, these regressions do include information from the mine with the disaster.
} 
find that the number of other workers is significantly higher in the year and state of the disaster, but that this coefficient is at most only marginally significantly positive in the years after a disaster. We find that the number of managers is significantly positive in the year of the disaster and two years after the disaster. On average, there are 280 more coal mining managers employed in a state in the second year after a disaster, which represents a $46 \%$ increase relative to the sample mean (Table 3). The overall number of workers also increases in the year of and second year after a disaster in the state. A possible explanation for our findings is that mines employ more managers and supervisors in the second year after a disaster in their state with the goal of reducing accident risk. The hiring of additional personnel who do not produce coal is consistent with our model that mines increase their safety labor input following an increase in the cost of accidents. It is inconsistent with a model where disasters lower accident rates because they result in workers doing the same set of activities, but more slowly.

Next, we turn to the effect of disasters on MSHA activity, with results reported in Figure 8. For each of the four enforcement variables, we find no pattern of significant variation in MSHA enforcement activity for mines in the same state as the disaster. The pre-trends here are also not significant. Thus, in the case of mine disasters, the causal pathway for changes in the cost of accidents does not appear to be extra MSHA enforcement activity. The lack of an effect of MSHA enforcement may be explained by the fact that it would difficult for MSHA to change its inspection frequencies on a widespread basis following a disaster without an increased budget for inspections, which could only be approved by a lengthy congressional budget approval process.

Robustness. Finally, we investigate several robustness measures for our main results that a disaster in a state lowers productivity and accident rates. Figure A.2 in Appendix A examines whether a disaster in a state has a long-run effect on productivity and safety, or whether the effect diminishes over time. We find that there is a persistent negative effect to productivity, though that effect is only significant at the $10 \%$ level. In contrast, we find no persistent long-run effects on any of the three types of accidents that we measure. Thus, our 
Figure 8: Effects of a disaster in state on MSHA activity
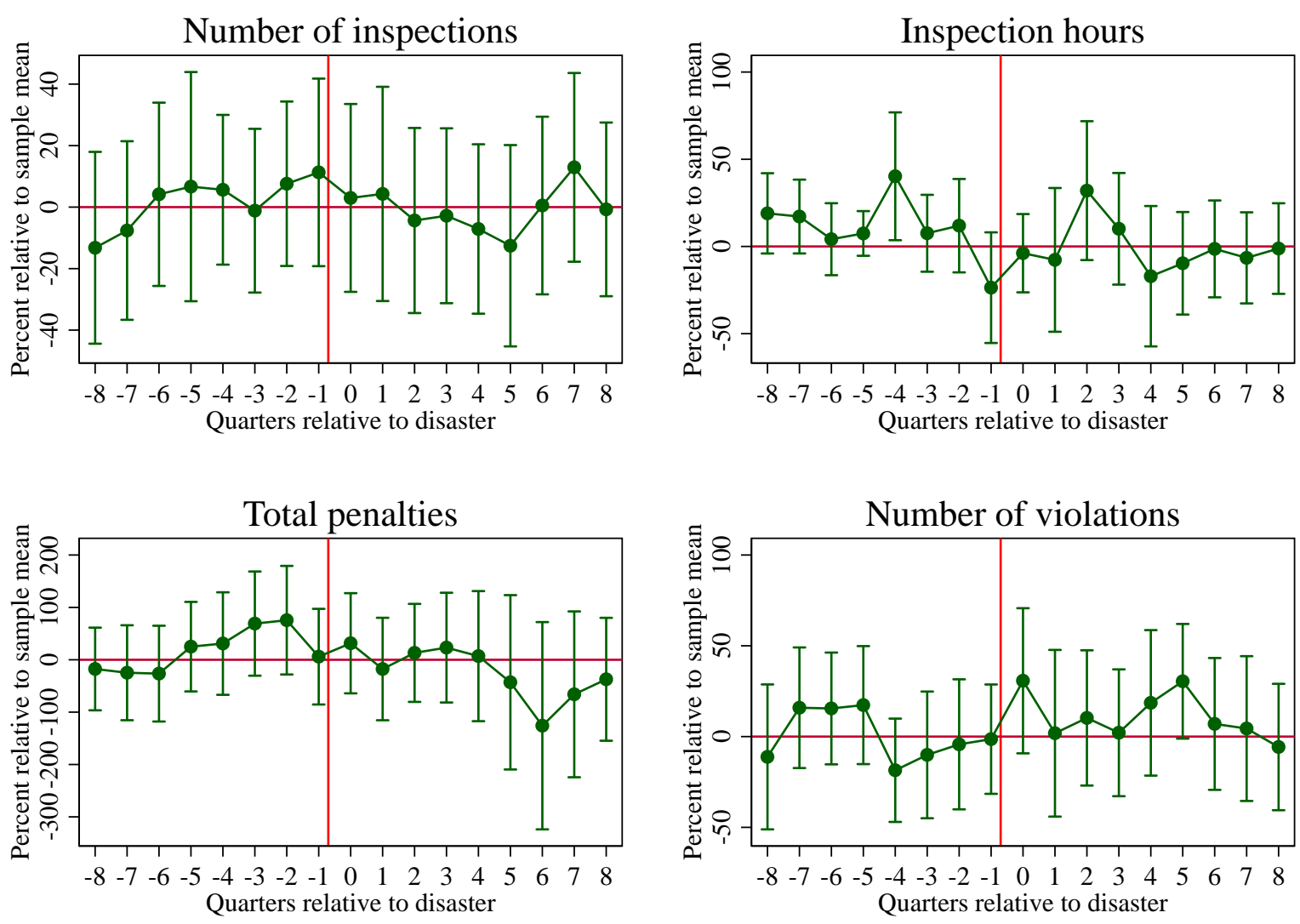

Note: each box reports selected regressors from one regression and each dot is a regression coefficient expressed as a percent of the sample mean of the regressor. Dependent variables are indicated in the titles. Each regression includes the following additional regressors: mine fixed effects, quarter fixed effects, state fixed effects interacted with hours worked, and state fixed effects interacted with number of employees, and is weighted by the mean number of workers at the mine. The vertical lines show $95 \%$ confidence intervals, based on standard errors clustered two ways at the state-quarter and mine levels.

base results may understate the loss in value from the higher cost of accidents, because they are more likely to understate the productivity loss than the safety gains.

We next consider the impact of a disaster on changing the relative price of safety based on the distance to the disaster, instead of being in the same state as the disaster. Figure A.3 considers the impact of having a disaster occur within 200KM of a mine and Figure A.4 considers the impact of a disaster within 400KM of a mine. Figure A.3 reports similar results to the base specifications in Figure 6. Figure A.4 reports results that are consistent 
with the base specifications but with less significance. Overall, the results suggest that the impact of a disaster on increasing the relative price of safety may extend to 200KM but diminishes by 400KM.

Next, Figure A.5 also evaluates whether the effect by which accidents and productivity decrease following a disaster in a state is selection, similar to Boomhower [2014]'s findings for oil drilling. In contrast to Boomhower, we find no significant impact of mine exit (defined as the last quarter in which the mine is in operation) on a disaster in a state. Figure A.6 uses the ACS data to examine whether there are changes in the mean income for employed coal mining workers following a disaster and in the state of the disaster. Though disasters predict a significantly lower income for some occupations in the first year after the disaster, none of the coefficients for the second year after the disaster are statistically significant. ${ }^{19}$

Finally, unreported in Appendix A, we also ran unweighted specifications (which no longer weight by average mine size) and specifications with fewer controls for mine size. We find very similar results to our base specifications.

\subsection{Effect of mine fatalities for underground coal mines}

We first seek to understand the impact of fatalities at a mine on productivity and measures of safety at that mine. Figure 9 presents results that are analogous to Figure 6, regressing productivity and safety measures on current, future, and lagged fatalities at the mine.

Here, we find that the rate of less-severe accidents per hour drops in the second year after the fatality. The mean drop in the four coefficients for the second year, at 6.1 fewer less-severe accidents per million hours worked, is about $14 \%$ of the sample mean. The coefficients on the rates of severe accidents and of fatalities are not significant. ${ }^{20}$ Neither are the coefficients on productivity. None of the pre-trends here are significant, supporting our causal interpretation.

Finally, we consider the impact of MSHA enforcement activity on a mine, with results in Figure 10. Here, similar to Figure 8, we report results from specifications that regress

\footnotetext{
${ }^{19}$ The income measure reported here is the previous year's income, and hence the negative income shocks in the year after the disaster may be caused by layoffs for workers at the mine with the disaster.

${ }^{20}$ The highly significant coefficients on the quarter of the fatality occurs because the fatality enters into these regressors.
} 
Figure 9: Effects of a mine fatality on productivity and safety
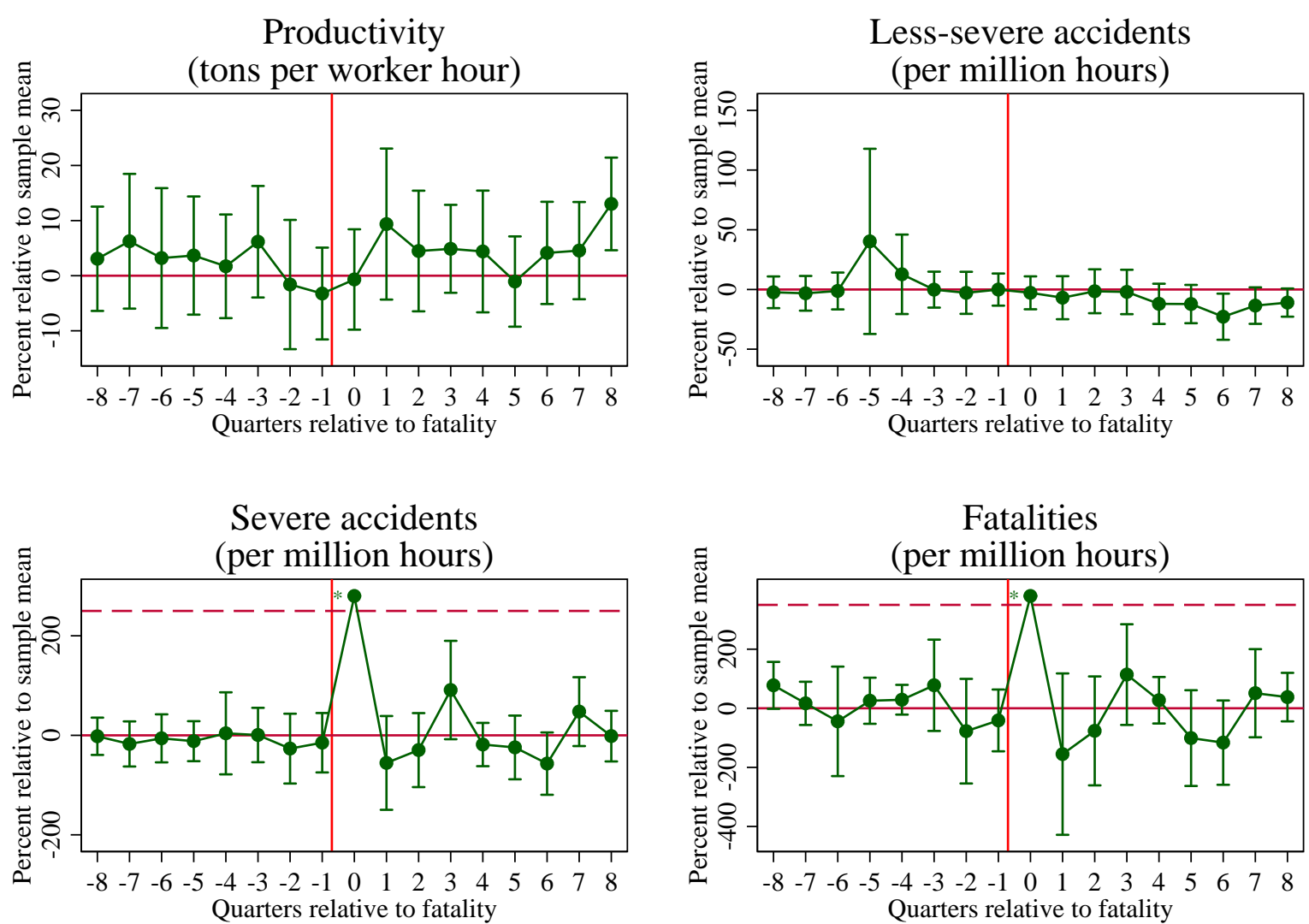

Note: each box reports selected regressors from one regression and each dot is a regression coefficient expressed as a percent of the sample mean of the regressor. Dependent variables are indicated in the titles. Each regression includes the following additional regressors: mine fixed effects, quarter fixed effects, state fixed effects interacted with hours worked, and state fixed effects interacted with number of employees, and is weighted by the mean number of workers at the mine. The vertical lines show $95 \%$ confidence intervals, based on standard errors clustered two ways at the state-quarter and mine levels. "** indicates a coefficient that is larger than the scale.

different MSHA enforcement actions on the presence of a current and lagged fatality at the mine.

We find that MSHA inspections, inspection hours, the number of violations, and penalties increase significantly in the year after a fatality at a mine. The magnitudes of the increases are large. For instance, the number of inspections increases by a mean of 1.9 in the first year after the fatality, representing a $31 \%$ increase relative to the sample mean, while the number 
Figure 10: Effects of a mine fatality on MSHA activity
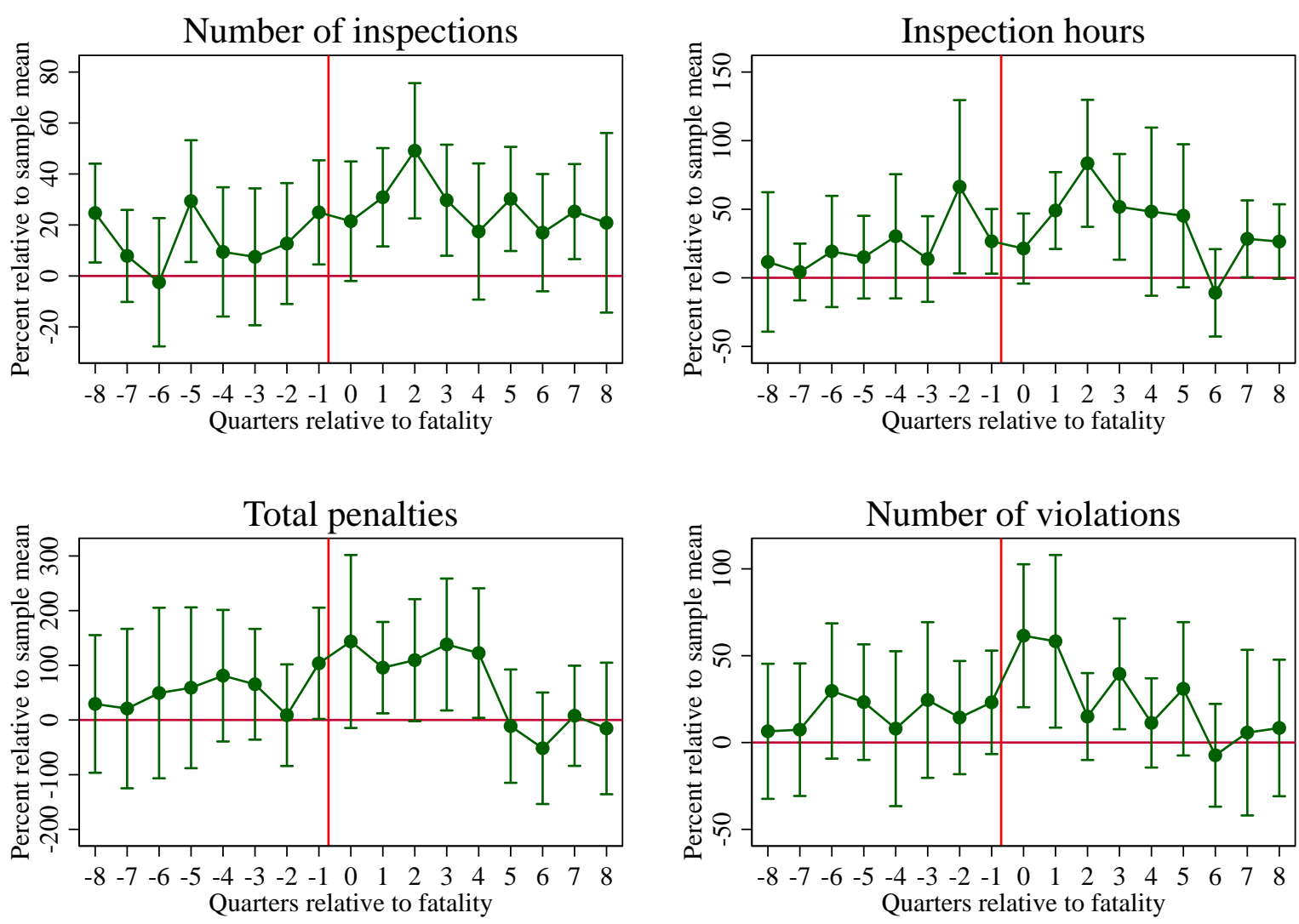

Note: each box reports selected regressors from one regression and each dot is a regression coefficient expressed as a percent of the sample mean of the regressor. Dependent variables are indicated in the titles. Each regression includes the following additional regressors: mine fixed effects, quarter fixed effects, state fixed effects interacted with hours worked, and state fixed effects interacted with number of employees, and is weighted by the mean number of workers at the mine. The vertical lines show $95 \%$ confidence intervals, based on standard errors clustered two ways at the state-quarter and mine levels.

of violations increases by a mean of 9.23 , representing a $47 \%$ increase. The pre-trends are not statistically significant, with some exceptions (notably in inspection hours in the two quarters before the fatality).

Interestingly, in the second year after the fatality, the effects are somewhat different. While the number of inspections and inspection hours are still significantly positive, the total penalties and number of violations both fall back to having much lower coefficients that are not statistically significant. We believe that this may be caused by mines reacting to the 
fatality and the increased MSHA enforcement activity by increasing their safety input.

Overall, the results support our hypothesis that mine fatalities are relatively rare events that shift the relative price of safety. However, the impact of a fatality at a mine appears to be quite different than the impact of a disaster near a mine. On the one hand, a fatality at a mine leads to big changes in MSHA enforcement for that mine. This is a plausible outcome since MSHA can redirect its inspections away from mines without fatalities and to mines with fatalities and may have a direct incentive to do this. On the other hand, a fatality at a mine leads to a much smaller change in safety or productivity than does a nearby disaster.

Robustness. We investigate whether our results are robust to fatalities among surface coal mines. We observe 151 fatalities among surface coal mines during our sample period. ${ }^{21}$ Figures A.7 and A.8 consider the analogs of Figures 9 and 10 respectively, but for surface coal mines. Unlike with underground coal mines, we do not find that a fatality at a mine predicts significantly lower future rates of less-severe accidents. We find similar results to underground coal mines regarding the impact of a fatality on the number of MSHA inspections and the inspection hours following the fatality. However, we find no significant increase in the total penalties or number of violations following a fatality. We believe that these results may be due to the relatively lower complexity of surface coal operations compared to underground coal mines, which may imply that it was easier to comply with MSHA regulations.

\subsection{Magnitudes of tradeoffs between productivity and safety}

We now turn to evaluating the dollar magnitudes of the tradeoffs between productivity and safety that we find. We focus on the tradeoffs imposed by the regulatory state following a disaster near a mine in the second year after a disaster, since these are the ones where there are statistically significant changes for both productivity and safety.

We first consider the lowered risk of fatality following a disaster in the state. There is a large literature on the value of a statistical life (VSL) that seeks to estimate the dollar value

\footnotetext{
${ }^{21}$ We did not perform this robustness exercise for disasters since we observe no disasters among surface coal mines during our sample period.
} 
equivalent of a lower mortality risk. A number of papers in this literature obtain estimates by estimating the wage premiums that workers earn from dangerous occupations such as mining, and dividing the wage premiums by the probability of death. An influential review article, Viscusi and Aldy [2003], finds that estimates of the VSL that use U.S. labor market data are between $\$ 4$ and $\$ 9$ million. Using their midpoint value of $\$ 6.5$ million, we find that the reduction in risk of fatalities from our Figure 6 mean estimates of -0.26 in the second year after the nearby disaster are equivalent to $\$ 1.69$ per hour worked. ${ }^{22}$

We next evaluate the cost savings from the lower risk of less-severe accidents following a disaster in the state. The National Safety Council estimates that the average cost of an accident which results in work absence is \$30,000 [National Safety Council, 2014]. Injuries resulting in work absence are our most common type of less-severe accidents (Table 1). This figure, together with our Figure 6 mean estimates of -7.93 in the second year after a disaster, imply a cost savings of $\$ 0.24$ per hour worked from the reduction in less-severe accidents in the second year after the disaster in the state. ${ }^{23}$

Viscusi and Aldy [2003] state that permanent disabilities should be valued similarly to fatalities. We do not account for potential reductions in severe accidents other than fatalities because the coefficient is not significant. Moreover, the coefficients on severe accidents in the second year after the disaster are similar to the coefficients on fatalities suggesting that the drop in the risk of severe accidents can be encapsulated by the estimated coefficient on the drop in the risk of fatalities. Overall, using VSL and similar estimates, the sum of our two figures above implies that the safety increases following a disaster near a mine would be equivalent to about $\$ 1.93$ per hour worked.

We next turn to the losses from the lower mineral productivity rates following a disaster in the same state as a mine. Suppose that, following a disaster near a mine, mines could hire extra workers to get back to their previous production level. In this case, since production per worker decreases by $10.8 \%$, the mine would need $12.1 \%$ more hours worked to achieve

\footnotetext{
${ }^{22}$ The VSL literature accounts for increased wage costs from accident risk but does not account for the direct cost of a large accident. The National Safety Council estimates a workplace fatality to cost $\$ 1.4$ million [National Safety Council, 2014].

${ }^{23}$ The cost savings from the lower risk of less-severe accidents in the second year after a fatality in a mine are equivalent to $\$ 0.18$ per hour worked.
} 
this production level. ${ }^{24}$ At a total cost of $\$ 40 /$ hour, ${ }^{25}$ this represents an extra $\$ 4.84$ in wages per current hour worked.

The assumption that mines could simply hire extra workers to make up for the productivity losses may underestimate the loss from the productivity drop. Suppose instead that mines reduced their production by $10.8 \%$, or 0.335 tons, per worker hour due to the disaster near the state. Since coal sells for about $\$ 50 /$ ton, ${ }^{26}$ the reduction in coal production would cost the mine about $\$ 16.75(=0.335 \times \$ 50)$ per hour worked. We believe that our first explanation is likely more credible, since the state-level data show an increase in coal mining workers in the year after the disaster. Nonetheless, it is worth pointing out that it is conservative relative to other potential explanations.

Combining our calculations, we find that the losses in productivity following a disaster near a mine are quite large and larger than the dollar value equivalent of the safety gains. Our conservative estimate of $\$ 4.84$ implies that the losses are equivalent to 2.51 times the gains in safety. It is also worth noting that two important factors point to the real-world value of the ratio being higher than this number. First, we find marginally significant longrun productivity drops but no significant long-run changes in accidents following a disaster. Second, the pre-trends on fatalities are large, negative, and in some cases significant, which implies that the causal effect is likely to be smaller than our reported effect.

Finally, note that we consider here only the changes in the tradeoffs between productivity and safety imposed by the current regulatory environment after a disaster near a mine. Moreover, our results reflect the mean effects and there is very likely heterogeneity across mines and mining companies in their tradeoffs between productivity and safety. In addition, our findings are consistent with the possibility that low-cost safety interventions, such as risk management, might lower accident risk by a large amount [Poplin et al., 2008], but that these

\footnotetext{
${ }^{24}$ We obtain this figure as $\frac{1}{1-10.8 \%}-1=12.1 \%$.

${ }^{25}$ The Bureau of Labor Statistics reports mean wages of $\$ 25.14$ for the occupation of "Construction and Extraction," \$25.10 for "Extraction Workers," and \$23.61 for "Transportation and Material Moving Occupations" [Table NAICS 212100 U.S. Bureau of Labor Statistics, 2014]. We find an annual mean wage and salary income of $\$ 61,000$ (Table 3) consistent with a $\$ 25$-30 wage. We assume that benefits cost $\$ 10$ to $\$ 15$ per hour.

${ }^{26}$ The average sales price of coal from underground mines in 2014 was $\$ 57$ per ton [see Energy Information Administration, 2015, Table 28].
} 
interventions are not chosen more after a disaster near a mine because they are not rewarded more by the regulatory state in this case.

\section{Conclusion}

Underground coal mining remains a dangerous sector where mines may be implicitly making tradeoffs between mineral production and safety. Mine regulation through MSHA is substantial in this sector, implying further that these tradeoffs may be affected by the regulatory state. This paper seeks to understand these tradeoffs. We hypothesize that a disaster near an underground coal mine, or a fatality at a mine, increases the relative cost of a future accident. We then use fatalities and disasters as sources of quasi-experimental variation that allow us to trace out the optimizing frontier between mineral productivity and safety. We believe that this approach to understanding the benefits and costs of regulation is novel and may be applicable to other sectors.

We find that a disaster leads to an $11 \%$ decrease in mineral productivity, an $18 \%$ decrease in the probability of less-severe accidents and an $80 \%$ decrease in the probability of fatalities in the second year after the disaster for mines in the state of the disaster. There is no significant change in MSHA inspections for these nearby mines. Using state-level data, we find evidence that the number of workers and managers in a state increases significantly in the second year after the disaster in the state. In the year following a fatality at a mine, MSHA inspections increase $31 \%$, but there is no drop in productivity and only a $14 \%$ drop in less-severe accidents in the second year after the fatality.

The loss in productivity costs mines $\$ 4.84$ per hour worked, using a conservative approach to this cost. Using published VSL numbers and costs of less-severe workplace injuries, the gains in safety are equivalent to $\$ 1.93$ per hour worked. Thus, the tradeoffs between productivity and safety are large and the dollar equivalent gains in safety following a disaster appear to be much less than the losses in productivity.

Overall, our results show that the regulatory state may be imposing a substantial burden on productivity for underground coal mines in order to ensure the regulated safety level. 
We believe that our paper may help guide regulators and policy makers in evaluating the marginal tradeoffs between mineral productivity and safety. Moreover, our result that the required safety level appears to increase following a disaster in a state is also of interest in understanding how the regulatory state functions.

\section{References}

J.R. Alford. Can government regulate safety? The coal mine example. American Political Science Review, 74:745-756, 1980.

Rabah Amir. Supermodularity and complementarity in economics: an elementary survey. Southern Economic Journal, pages 636-660, 2005.

Judson Boomhower. Drilling like there's no tomorrow: bankruptcy, insurance, and environmental risk. EI@Haas Working Paper, 254, 2014.

Benjamin Bridgman, Shi Qi, James A Schmitz, et al. Does regulation reduce productivity? Evidence from regulation of the US beet-sugar manufacturing industry during the sugar acts, 1934-74. Technical report, Federal Reserve Bank of Minneapolis Research Department, 2007.

John Brophy and John OP Hall. A Miner's Life: An Autobiography. University of Wisconsin Press, 1964.

Bentley Coffey, Patrick A McLaughlin, and Pietro F Peretto. The cumulative cost of regulations. 2016. URL https://www.mercatus .org/system/files/Coffey-Cumulative-Cost-Regs-v3. pdf. Mercatus Working Paper, accessed: Feb. 1, 2017.

Energy Information Administration. Annual Coal Report 2014. U.S. Department of Energy, 2015.

John G Everett and Alexander H Slocum. Cranium: device for improving crane productivity and safety. Journal of Construction Engineering and Management, 119(1):23-39, 1993.

Fred E Fiedler, Cecil H Bell Jr, Martin M Chemers, and Dennis Patrick. Increasing mine productivity and safety through management training and organization development: A comparative study. Basic and Applied Social Psychology, 5(1):1-18, 1984. 
Price V Fishback. Soft Coal, Hard Choices. New York: Oxford University Press, 1992.

Trip Gabriel. Ex-executive Donald Blankenship is indicted in disaster at coal mine. The New York Times, 2014. URL https://www.nytimes.com/2014/11/14/us/ ex-executive-donald-blankenship-is-indicted-in-disaster-at-coal-mine.html?_r=0. Accessed Feb. 1, 2017.

Nicole Goodkind. Trump says he 'saved coal,' but miner deaths nearly doubled in his first year. Newsweek, 2018. URL http://www.newsweek.com/ coal-miners-safety-health-trump-788576. Accessed Jan. 28, 2018.

Wayne B Gray. The cost of regulation: OSHA, EPA and the productivity slowdown. The American Economic Review, 77(5):998-1006, 1987.

Michael Greenstone, John A List, and Chad Syverson. The effects of environmental regulation on the competitiveness of us manufacturing. NBER Working Paper 18468, 2012.

Catherine Hausman. Corporate incentives and nuclear safety. American Economic Journal: Economic Policy, 6:178-206, 2014.

Igal Hendel and Yossi Spiegel. Small steps for workers, a giant leap for productivity. American Economic Journal: Applied Economics, 6(1):73-90, 2014.

D.A. Hensher, R. Daniels, and H. Battellino. Safety and productivity in the long distance trucking industry. In Proceeding, 16th ARRB Conference, 9-13 November 1992, Perth, Western Australia; Vol 16, PART 4, 1992.

Thomas J Kniesner and John D Leeth. Data mining mining data: MSHA enforcement efforts, underground coal mine safety, and new health policy implications. Journal of Risk and Uncertainty, 29(2):83-111, 2004.

Taylor Kuykendall and Rizwan Qureshi. US coal industry challenged by over a decade of declining productivity. 2014. URL http://www.wvpolicy.org/wp-content/uploads/2014/10/snlpdf_ 448ee5a0-d91f-447d-aa69-32d27d883b59.pdf. Accessed Feb. 1, 2017. 
Jonathan Lee and Laura Taylor. Randomized safety inspections and risk exposure on the job: quasi-experimental estimates of the value of a statistical life. 2014.

J Paul Leigh, James P Marcin, and Ted R Miller. An estimate of the US governments undercount of nonfatal occupational injuries. Journal of Occupational and Environmental Medicine, 46(1): $10-18,2004$.

David I Levine, Michael W Toffel, and Matthew S Johnson. Randomized government safety inspections reduce worker injuries with no detectable job loss. Science, 336(6083):907-911, 2012.

Barry Meier and Danielle Ivory. Worker safety rules are among those under fire in Trump era. The New York Times, 2017. URL https://www.nytimes.com/2017/03/13/business/ us-worker-safety-rules-osha.html. Accessed Mar. 24, 2017.

Niccolò Brachetti Montorselli, Carolina Lombardini, Natascia Magagnotti, Enrico Marchi, Francesco Neri, Gianni Picchi, and Raffaele Spinelli. Relating safety, productivity and company type for motor-manual logging operations in the Italian Alps. Accident Analysis 8 Prevention, 42(6): 2013-2017, 2010.

National Safety Council. Injury Facts 2014 Edition. National Safety Council, 2014.

Barack Obama. Remarks by the President on mine safety, 04 2010. URL http://www . whitehouse. gov/the-press-office/remarks-president-mine-safety. Accessed Jan. 30, 2015.

Gerald S Poplin, Hugh B Miller, James Ranger-Moore, Carmel M Bofinger, Margaret KurziusSpencer, Robin B Harris, and Jefferey L Burgess. International evaluation of injury rates in coal mining: A comparison of risk and compliance-based regulatory approaches. Safety Science, 46 (8):1196-1204, 2008.

L. Rittenberg and E.H. Manuel, Jr. Sources of labor productivity variation in the US surface coal mining industry, 1960-1976. The Energy Journal, pages 87-100, 1987.

Steven Ruggles, J. Trent Alexander, Katie Genadek, Ronald Goeken, Matthew B. Schroeder, and Matthew Sobek. Integrated public use microdata series: Version 5.0, 2010. URL https://usa. ipums.org/usa/cite.shtml. Accessed: Apr. 20, 2015. 
E. Sawacha, S. Naoum, and D. Fong. Factors affecting safety performance on construction sites. International Journal of Project Management, 17(5):309-315, 1999.

James A Schmitz. What determines productivity? Lessons from the dramatic recovery of the US and Canadian iron ore industries following their early 1980s crisis. Journal of Political Economy, 113(3):582-625, 2005.

Hal Sider. Safety and productivity in underground coal mining. The Review of Economics and Statistics, pages 225-233, 1983.

The Editorial Board. Compounding the risk for coal miners. The New York Times, 2017. URL https://www.nytimes.com/2017/03/20/opinion/ compounding-the-risk-for-coal-miners.html. Accessed Mar. 24, 2017.

Susan F Tierney. The US coal industry: Challenging transitions in the 21st century. 2016. URL http://www . analysisgroup.com/uploadedfiles/content/insights/publishing/tierney $\% 20-\backslash \% 20$ coal $\backslash \% 20$ industry $\backslash \% 20-\backslash \% 2021$ st $\backslash \% 20$ century $\backslash \% 20$ challenges $\backslash \% 209-26-2016$. pdf. Accessed Feb. 1, 2017.

Donald M Topkis. Minimizing a submodular function on a lattice. Operations research, 26(2): 305-321, 1978.

U.S. Bureau of Labor Statistics. May 2013 OES national industry-specific occupational employment and wage estimates, April 2014. URL http://www.bls.gov/oes/current/oes_ind.htm. Accessed: Feb. 10, 2015.

W Kip Viscusi and Joseph E Aldy. The value of a statistical life: a critical review of market estimates throughout the world. Journal of Risk and Uncertainty, 27(1):5-76, 2003.

James L Weeks and Maier Fox. Fatality rates and regulatory policies in bituminous coal mining, United States, 1959-1981. American Journal of Public Health, 73(11):1278-1280, 1983. 


\section{Appendix A: Supplementary figures and tables}

Figure A.1: Total underground coal production by state

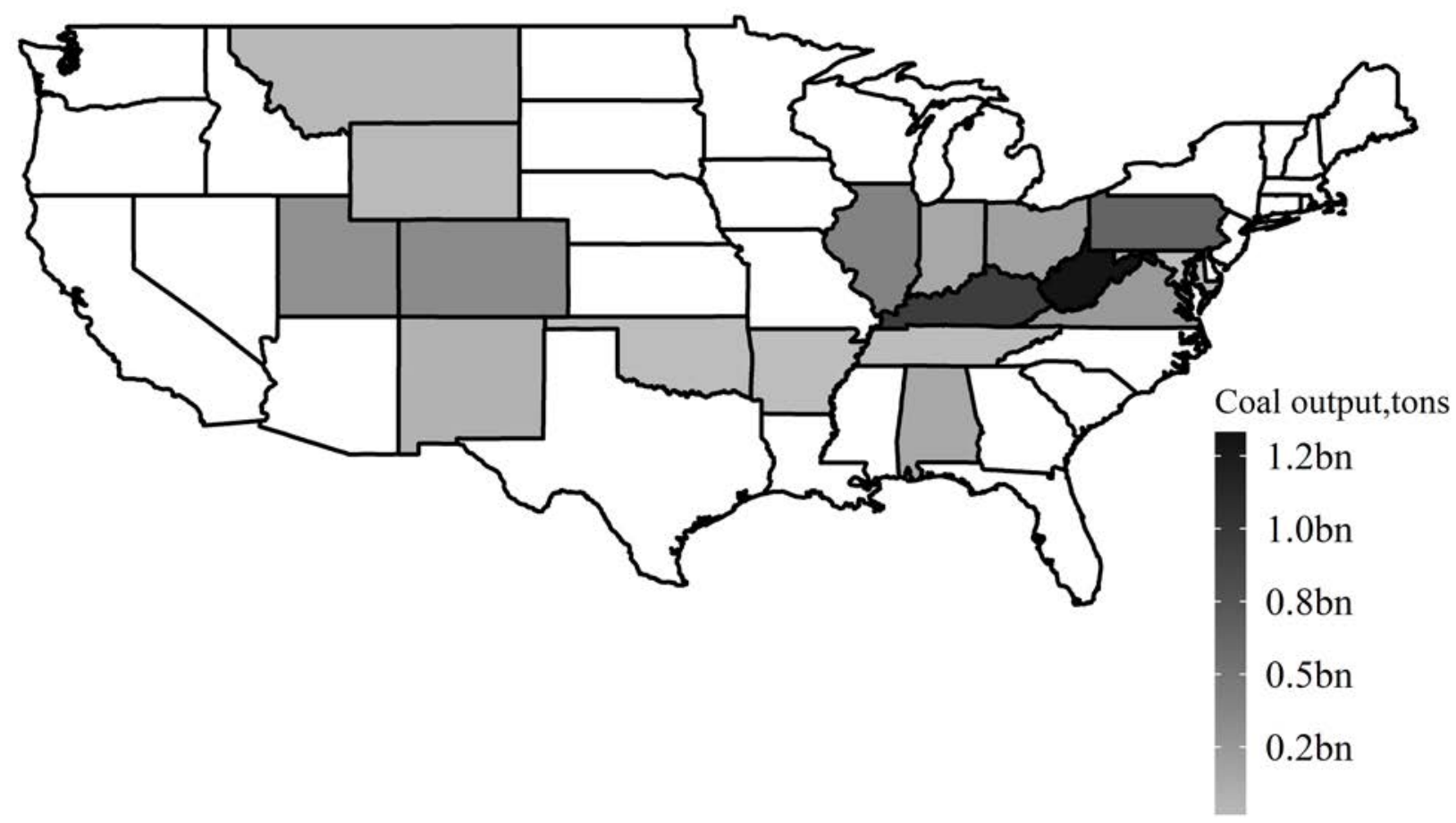

Note: figure based on authors' calculations from estimation sample. 
Figure A.2: Effects of a disaster in a state on productivity and safety, with long-run effects
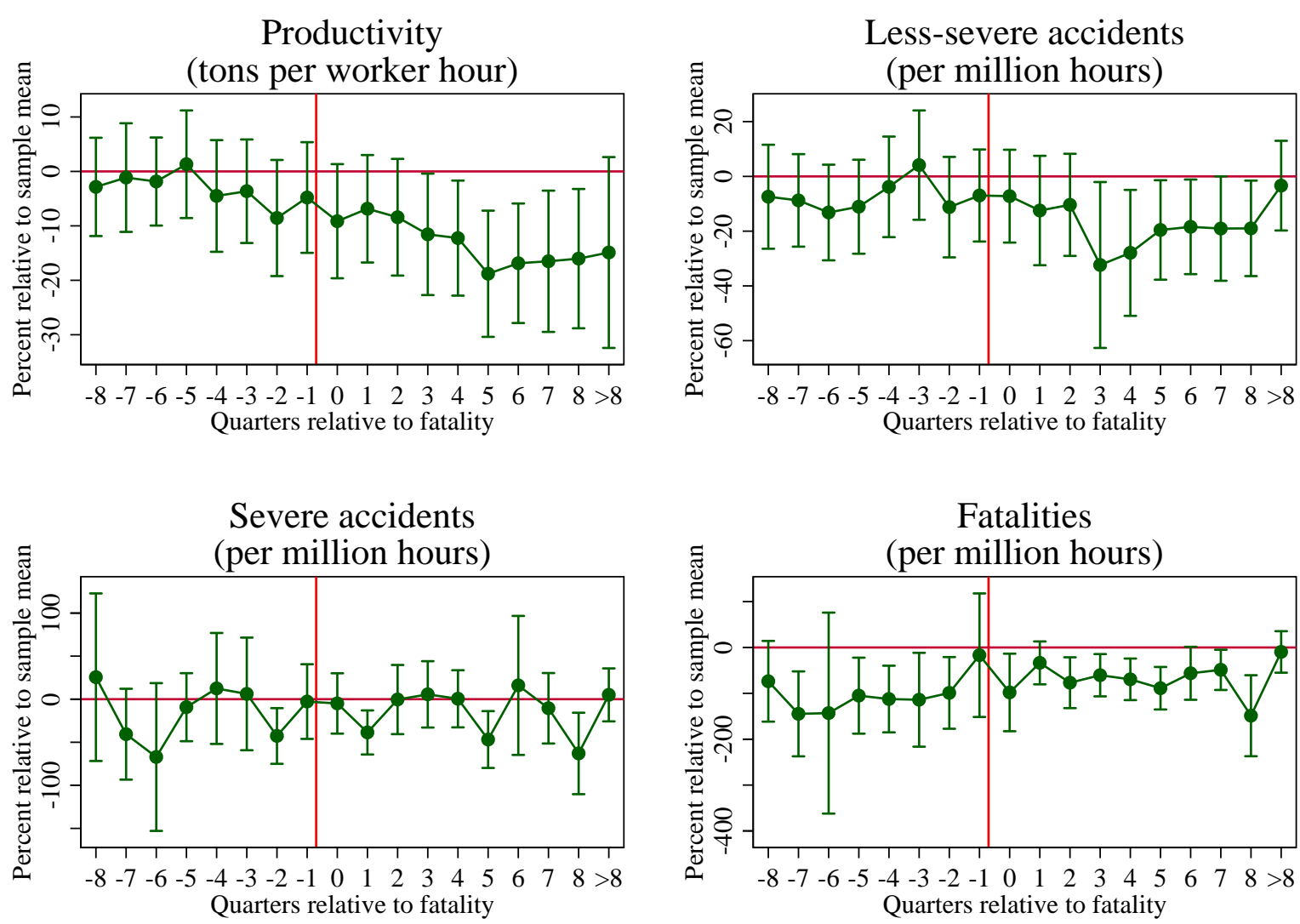

Note: each box reports selected regressors from one regression and each dot is a regression coefficient expressed as a percent of the sample mean of the regressor. Dependent variables are indicated in the titles. Each regression includes the following additional regressors: mine fixed effects, quarter fixed effects, state fixed effects interacted with hours worked, and state fixed effects interacted with number of employees, and is weighted by the mean number of workers at the mine. The vertical lines show $95 \%$ confidence intervals, based on standard errors clustered two ways at the state-quarter and mine levels. 
Figure A.3: Effects of a disaster within 200KM on productivity and safety
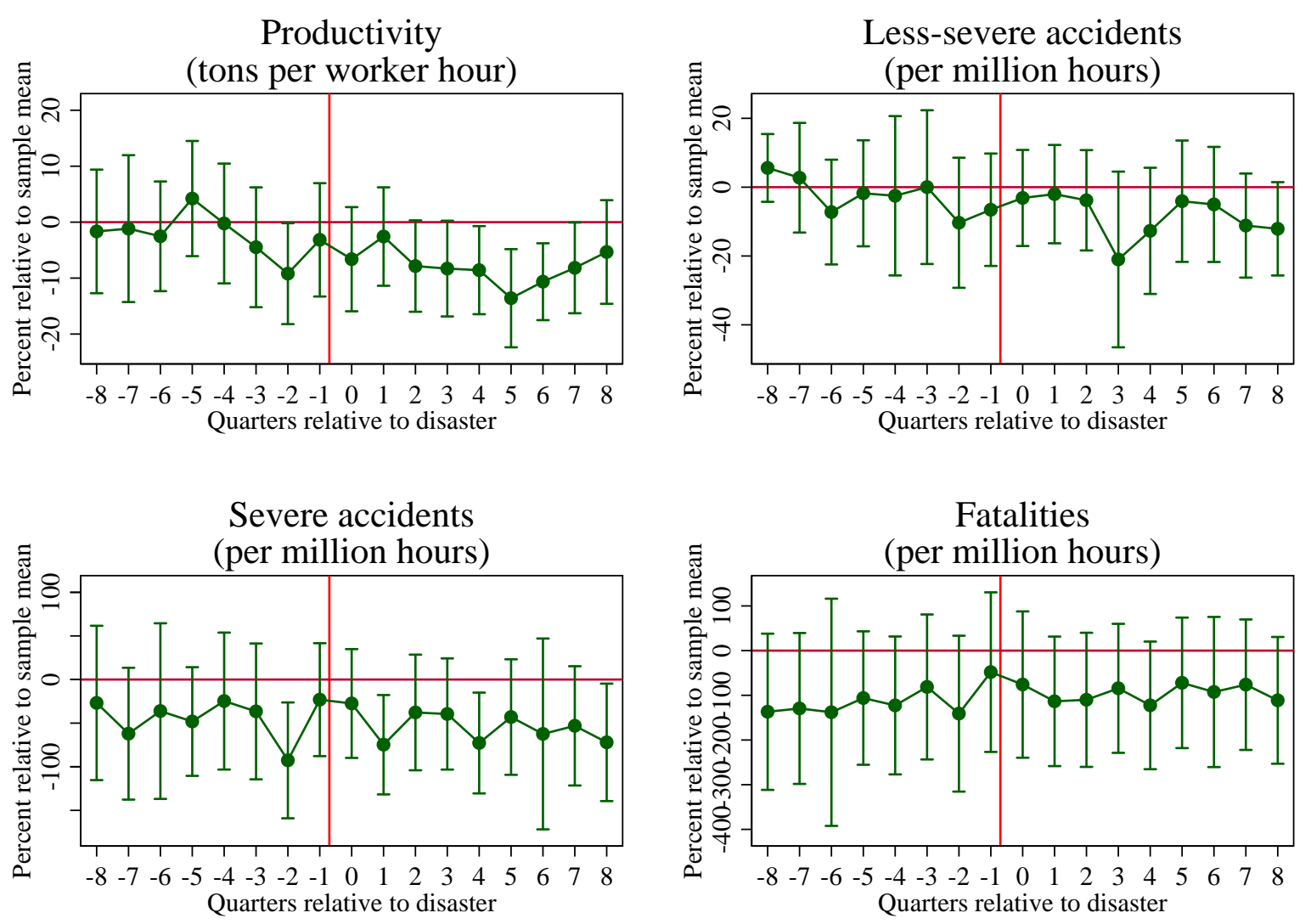

Note: each box reports selected regressors from one regression and each dot is a regression coefficient expressed as a percent of the sample mean of the regressor. Dependent variables are indicated in the titles. Each regression includes the following additional regressors: mine fixed effects, quarter fixed effects, state fixed effects interacted with hours worked, and state fixed effects interacted with number of employees, and is weighted by the mean number of workers at the mine. The vertical lines show $95 \%$ confidence intervals, based on standard errors clustered two ways at the state-quarter and mine levels. 
Figure A.4: Effects of a disaster within 400KM on productivity and safety
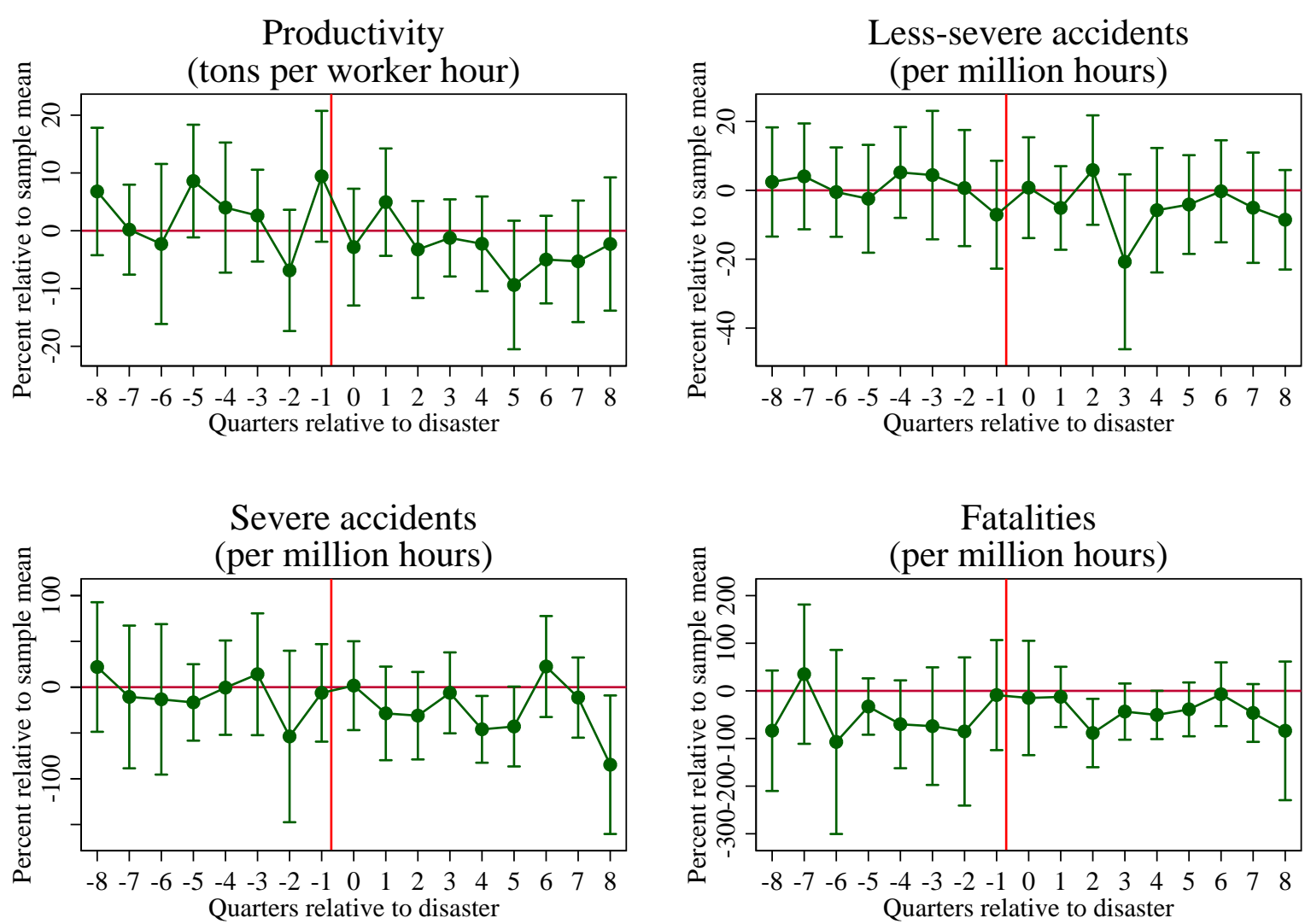

Note: each box reports selected regressors from one regression and each dot is a regression coefficient expressed as a percent of the sample mean of the regressor. Dependent variables are indicated in the titles. Each regression includes the following additional regressors: mine fixed effects, quarter fixed effects, state fixed effects interacted with hours worked, and state fixed effects interacted with number of employees, and is weighted by the mean number of workers at the mine. The vertical lines show $95 \%$ confidence intervals, based on standard errors clustered two ways at the state-quarter and mine levels. 
Figure A.5: Effects of a disaster in state on mine exit

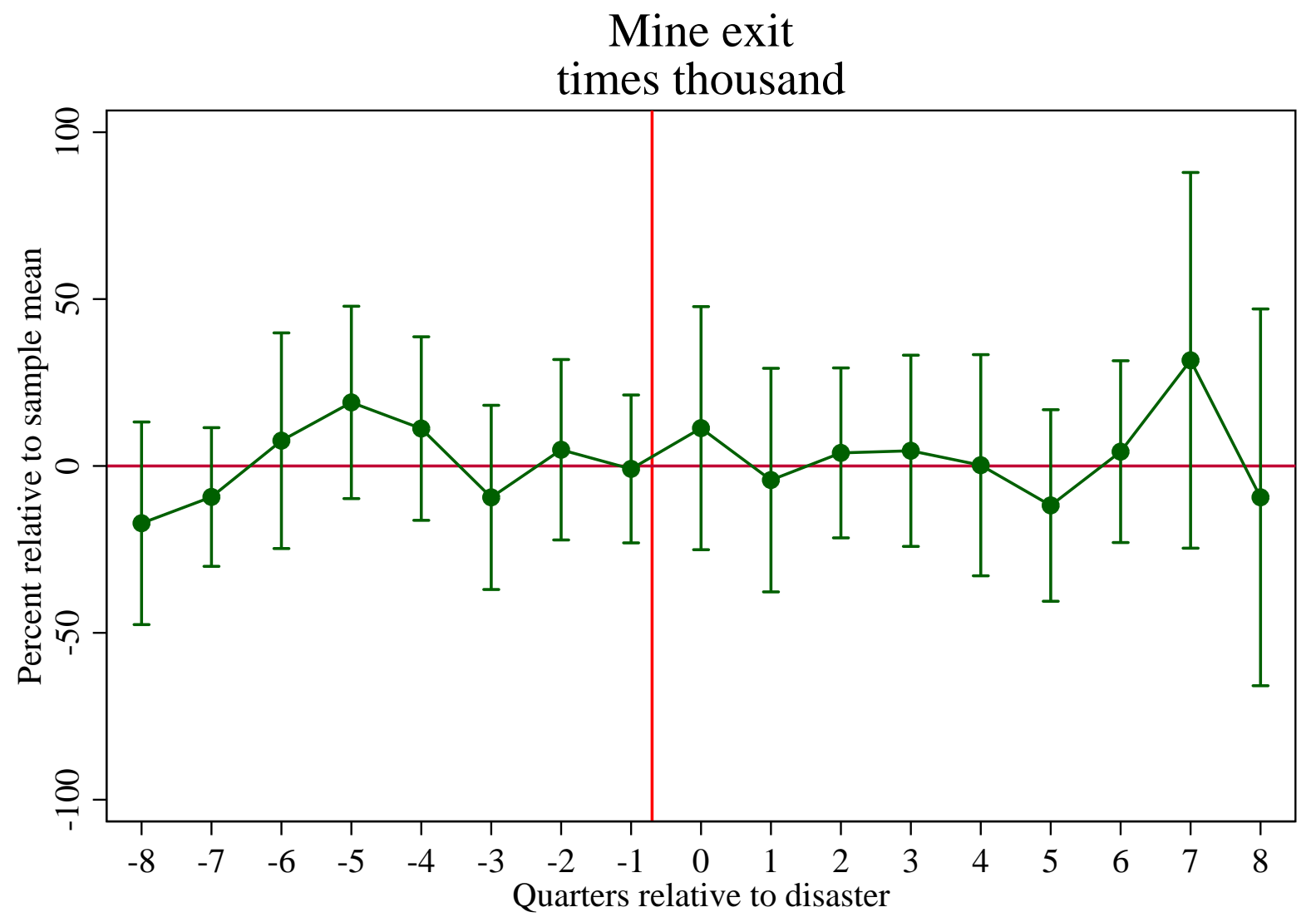

Note: each box reports selected regressors from one regression and each dot is a regression coefficient expressed as a percent of the sample mean of the regressor. Dependent variables are indicated in the titles. Each regression includes the following additional regressors: mine fixed effects, quarter fixed effects, state fixed effects interacted with hours worked, and state fixed effects interacted with number of employees, and is weighted by the mean number of workers at the mine. The vertical lines show $95 \%$ confidence intervals, based on standard errors clustered two ways at the state-quarter and mine levels. 
Figure A.6: Effects of a disaster on mean income of employed coal mining workers in state, by category
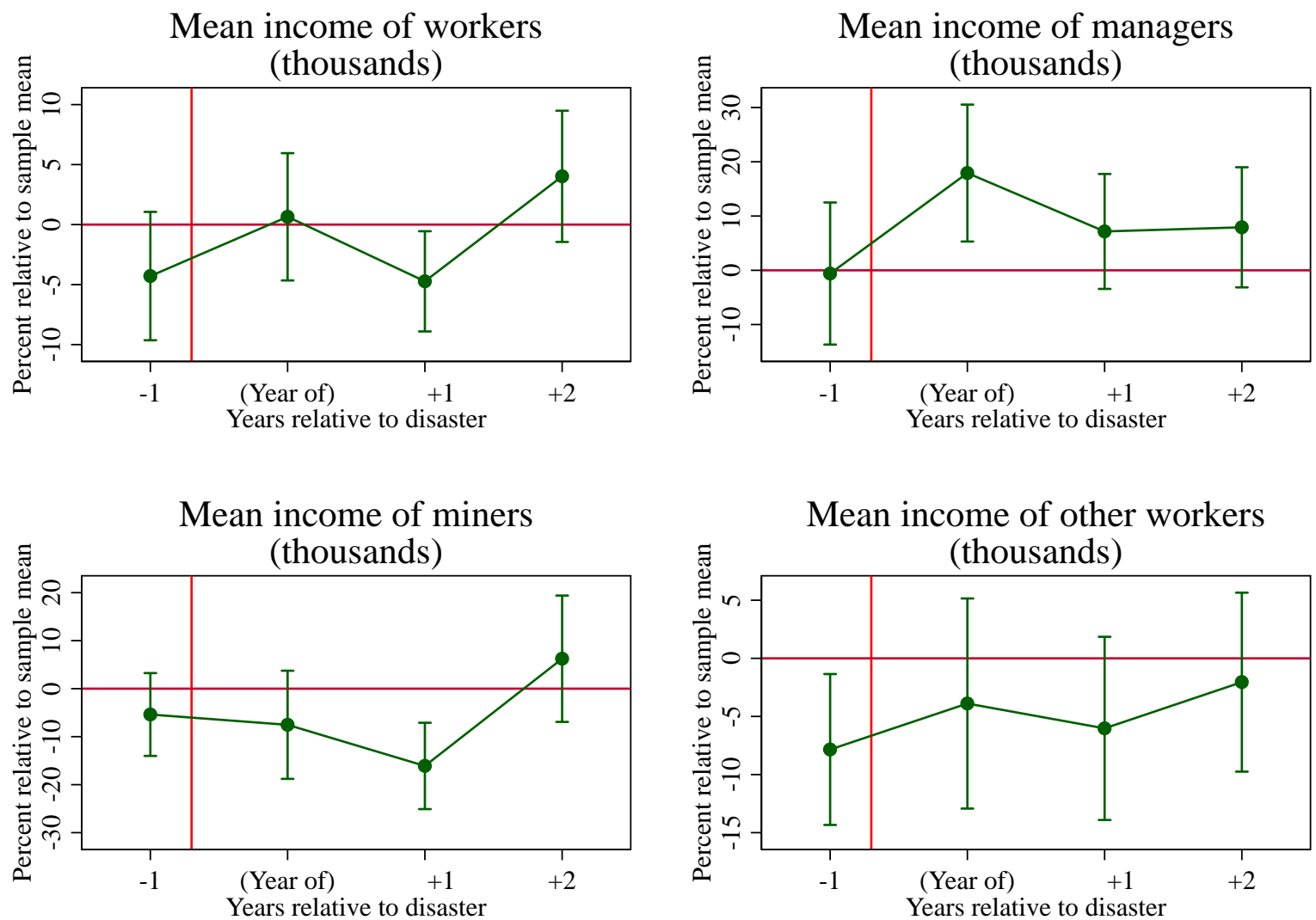

Note: regressions use state-year level ACS data. Each box reports selected regressors from one regression and each dot is a regression coefficient expressed as a percent of the sample mean of the regressor. Dependent variables are indicated in the title. Each regression includes the following additional regressors: state fixed effects, year fixed effects, and logged state GDP per capita, and is weighted by the mean number of workers in the state. Standard errors are clustered at the state level. 
Figure A.7: Effects of a mine fatality on productivity and safety for surface mines
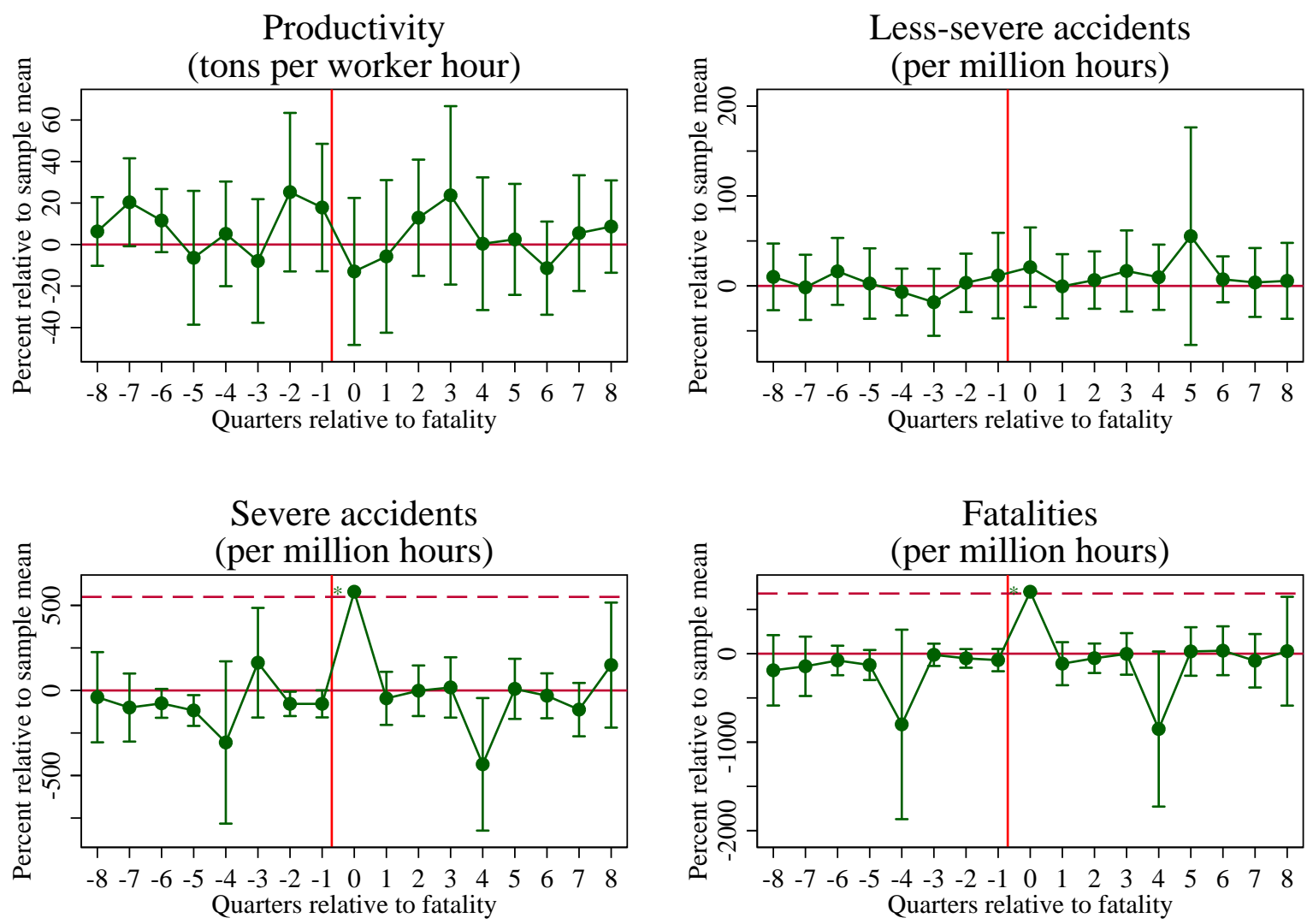

Note: each box reports selected regressors from one regression and each dot is a regression coefficient expressed as a percent of the sample mean of the regressor. Dependent variables are indicated in the titles. Each regression includes the following additional regressors: mine fixed effects, quarter fixed effects, state fixed effects interacted with hours worked, and state fixed effects interacted with number of employees, and is weighted by the mean number of workers at the mine. The vertical lines show $95 \%$ confidence intervals, based on standard errors clustered two ways at the state-quarter and mine levels. "*" indicates a coefficient that is larger than the scale. 
Figure A.8: Effects of a mine fatality on MSHA activity for surface mines
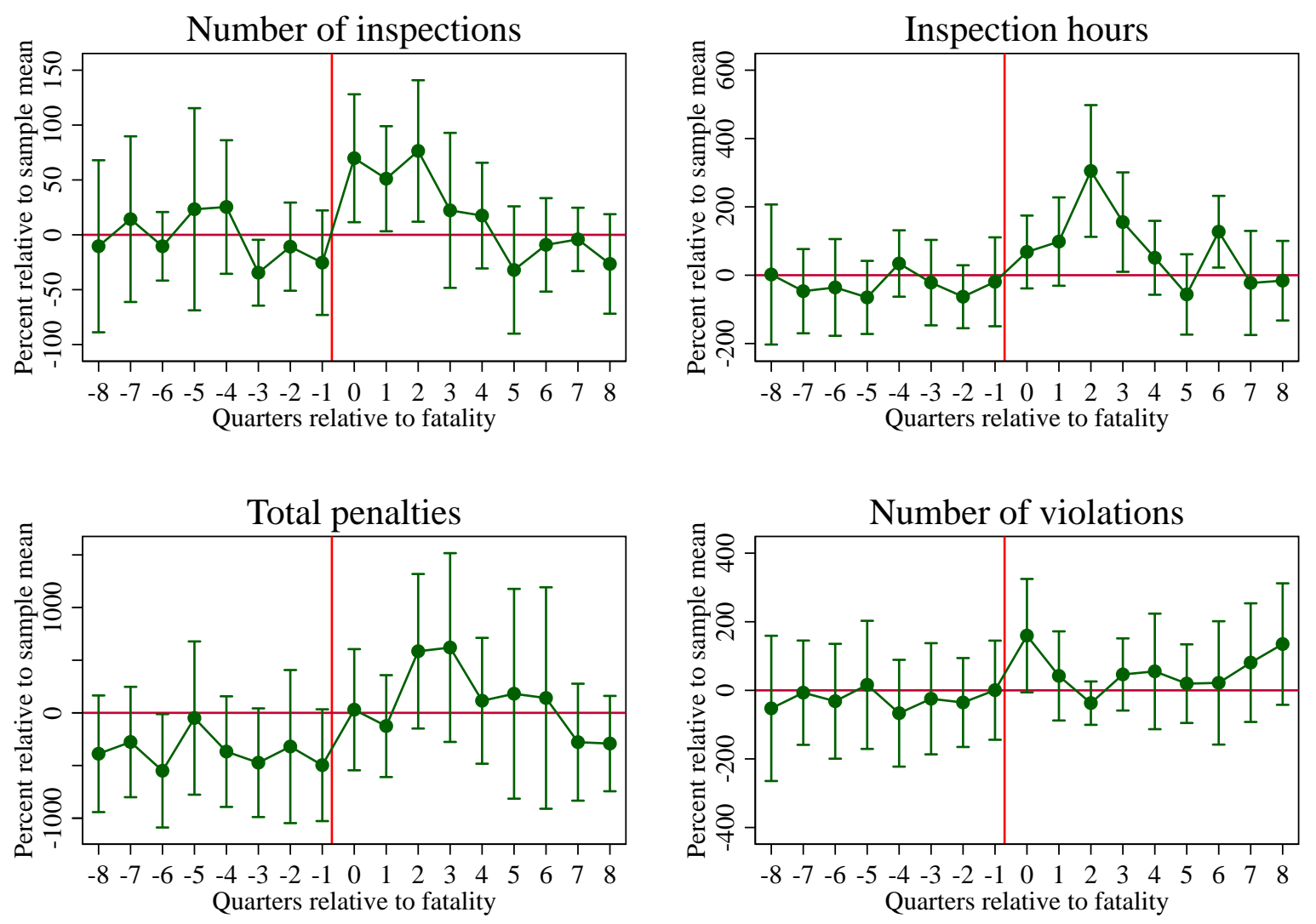

Note: each box reports selected regressors from one regression and each dot is a regression coefficient expressed as a percent of the sample mean of the regressor. Dependent variables are indicated in the titles. Each regression includes the following additional regressors: mine fixed effects, quarter fixed effects, state fixed effects interacted with hours worked, and state fixed effects interacted with number of employees, and is weighted by the mean number of workers at the mine. The vertical lines show $95 \%$ confidence intervals, based on standard errors clustered two ways at the state-quarter and mine levels. 
Table A.1: Coefficient table for effects of a disaster in state on productivity and safety

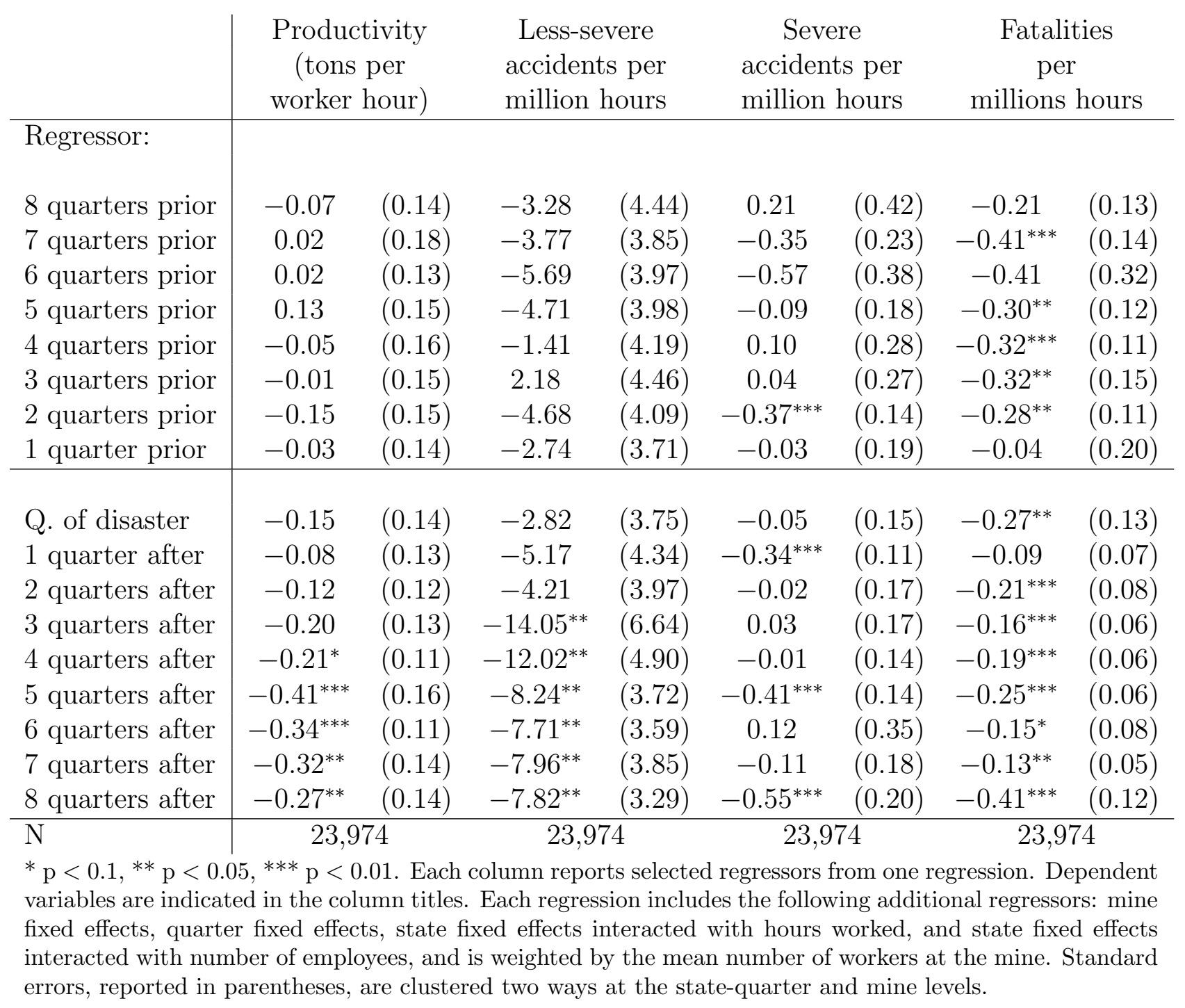


Table A.2: Coefficient table for effects of a disaster on the number of coal mining workers in state, by category

\begin{tabular}{|c|c|c|c|c|}
\hline & $\begin{array}{l}\text { Total number } \\
\text { of workers } \\
\text { (thousands) }\end{array}$ & $\begin{array}{l}\text { Number of } \\
\text { managers } \\
\text { (thousands) }\end{array}$ & $\begin{array}{l}\text { Number of } \\
\text { miners } \\
\text { (thousands) }\end{array}$ & $\begin{array}{l}\text { Number of } \\
\text { other workers } \\
\text { (thousands) }\end{array}$ \\
\hline \multicolumn{5}{|l|}{ Regressor: } \\
\hline 1 year prior & $\begin{array}{l}-0.55 \\
(0.58)\end{array}$ & $\begin{array}{l}-0.17 \\
(0.17)\end{array}$ & $\begin{array}{l}-0.72 \\
(0.54)\end{array}$ & $\begin{array}{c}0.33 \\
(0.90)\end{array}$ \\
\hline Year of disaster & $\begin{array}{c}2.43^{* * *} \\
(0.42)\end{array}$ & $\begin{array}{c}0.47^{* * *} \\
(0.13)\end{array}$ & $\begin{array}{l}-0.22 \\
(0.52)\end{array}$ & $\begin{array}{c}2.19^{* * *} \\
(0.66)\end{array}$ \\
\hline 1 year after & $\begin{array}{c}0.56 \\
(0.56)\end{array}$ & $\begin{array}{c}0.09 \\
(0.22)\end{array}$ & $\begin{array}{c}-0.55^{* * *} \\
(0.21)\end{array}$ & $\begin{array}{c}1.02 \\
(0.85)\end{array}$ \\
\hline 2 years after & $\begin{array}{c}2.58^{* * *} \\
(0.34)\end{array}$ & $\begin{array}{c}0.28^{* * *} \\
(0.06)\end{array}$ & $\begin{array}{c}0.98 \\
(0.69)\end{array}$ & $\begin{array}{l}1.32^{*} \\
(0.69)\end{array}$ \\
\hline $\begin{array}{l}\mathrm{R}^{2} \text { within } \\
\mathrm{N}\end{array}$ & $\begin{array}{l}0.55 \\
219\end{array}$ & $\begin{array}{l}0.37 \\
219\end{array}$ & $\begin{array}{l}0.40 \\
219\end{array}$ & $\begin{array}{l}0.36 \\
219\end{array}$ \\
\hline
\end{tabular}

${ }^{*} \mathrm{p}<0.1,{ }^{* *} \mathrm{p}<0.05,{ }^{* * *} \mathrm{p}<0.01$. Regressions use state-year level ACS data. Each regression includes the following additional regressors: state fixed effects, year fixed effects, and logged state GDP per capita, and is weighted by the mean number of workers in the state. Standard errors, reported in parentheses, are clustered at the state level. 
Table A.3: Coefficient table for effects of a disaster in state on MSHA activity

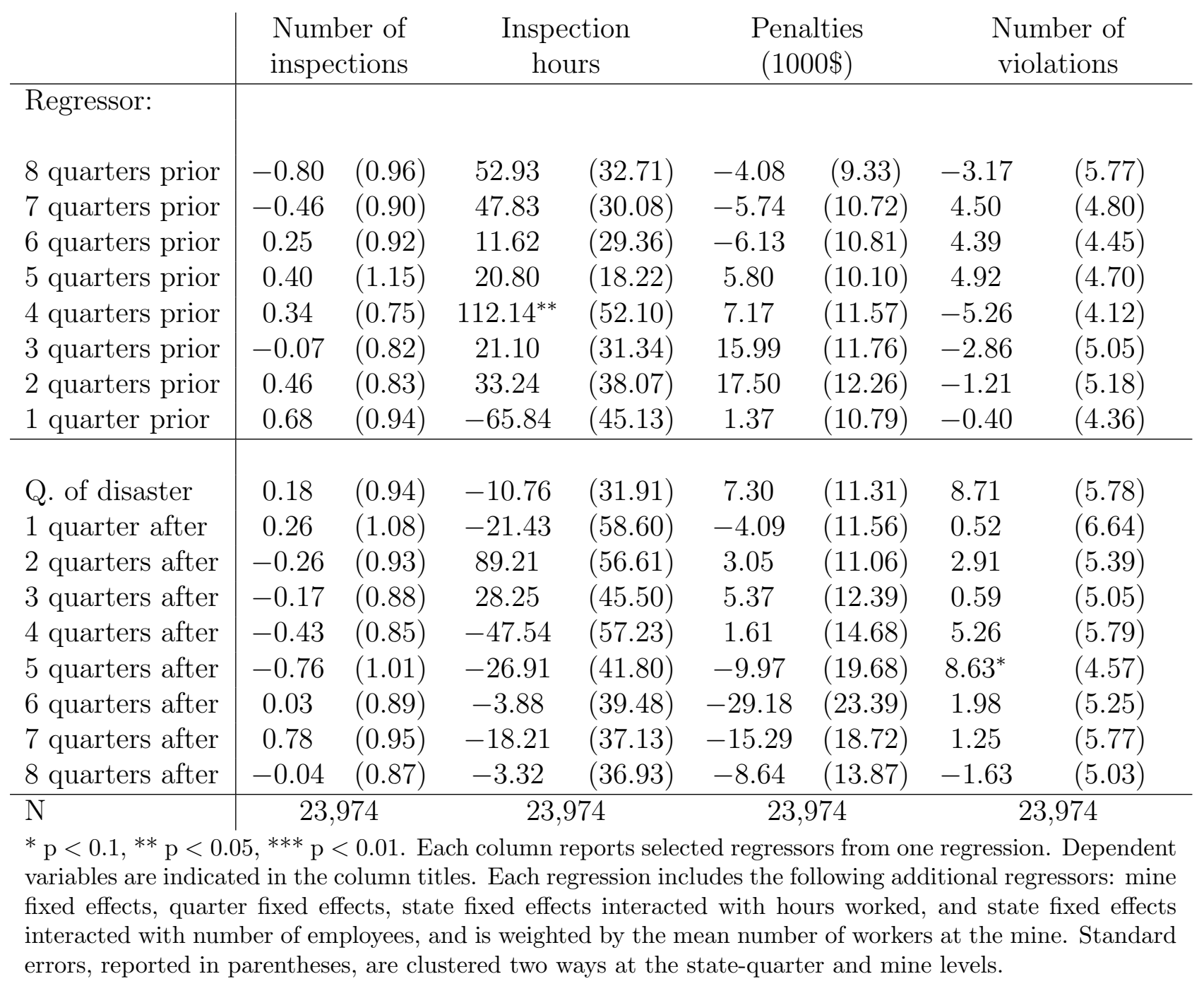


Table A.4: Coefficient table for effects of a mine fatality on productivity and safety

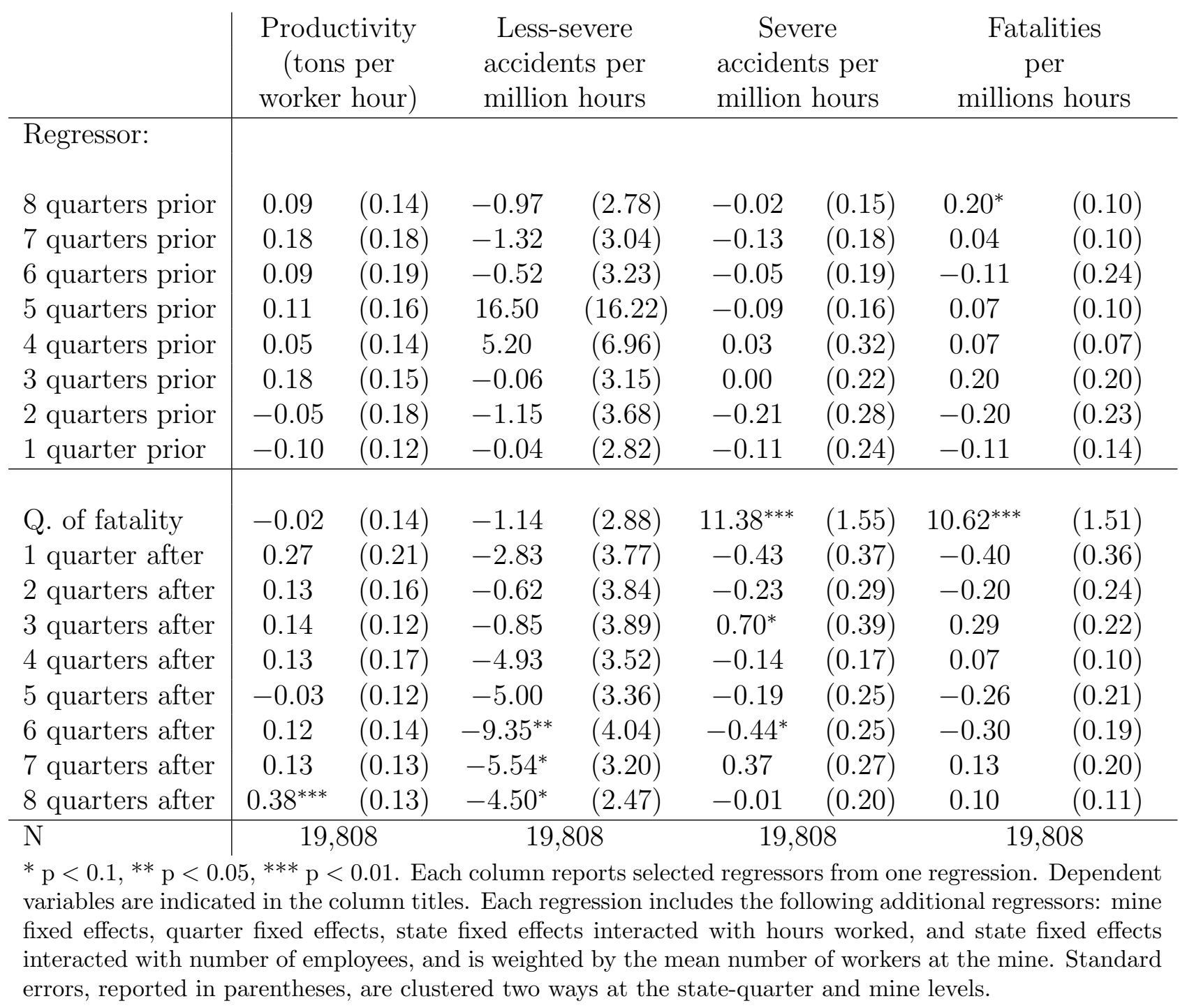


Table A.5: Coefficient table for effects of a mine fatality on MSHA activity

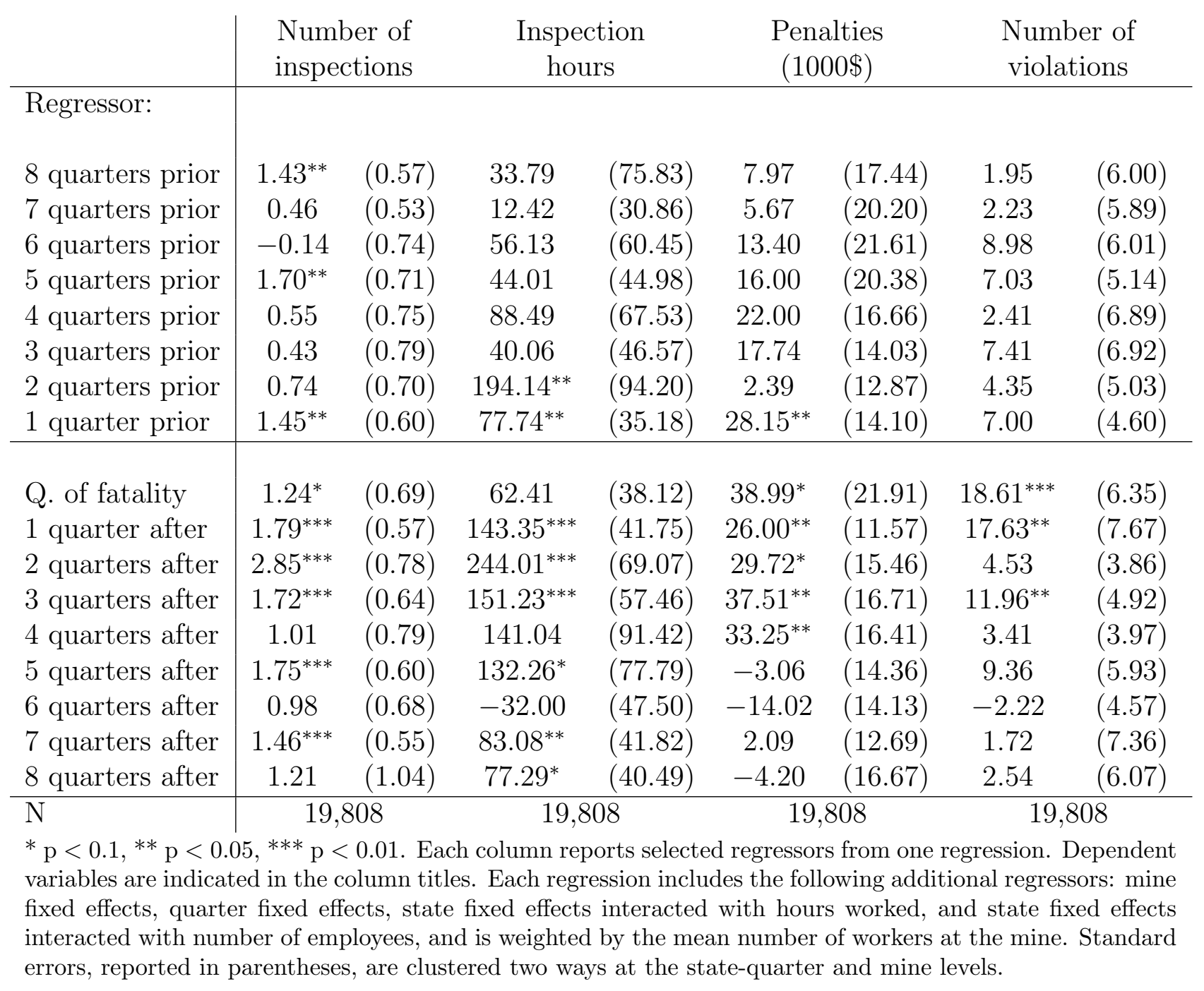

